\title{
Whole-Genome Sequencing and Comparative Genomic Analysis of Potential Biotechnological Strains from Trichoderma harzianum, Trichoderma atroviride, and Trichoderma reesei
} Anete Pereira de Souza ${ }^{1,3 *}$

${ }^{1}$ Center for Molecular Biology and Genetic Engineering (CBMEG), University of Campinas (UNICAMP), Cidade Universitária Zeferino Vaz, Campinas, SP, Brazil

${ }^{2}$ Graduate Program in Genetics and Molecular Biology, Institute of Biology, UNICAMP, Campinas, SP, Brazil

${ }^{3}$ Department of Plant Biology, Institute of Biology, UNICAMP, Cidade Universitária Zeferino Vaz, Rua Monteiro Lobato, Campinas, SP, Brazil

${ }^{4}$ Faculty of Pharmaceutical Sciences of Ribeirão Preto, University of São Paulo (USP), Ribeirão Preto, SP, Brazil

\section{* Correspondence:}

Anete Pereira de Souza

anete@unicamp.br

Number of words: 5644

Number of figures: 7

\section{Number of tables: 3}

Keywords: Trichoderma, genomes, comparative analysis, orthology analysis, structural variant analysis

\section{Abstract}

Fungi of the genus Trichoderma exhibit high genetic diversity and can thus be utilized in a large range of biotechnological applications. While Trichoderma reesei is the primary source of industrial enzymatic cocktails, Trichoderma atroviride and Trichoderma harzianum are widely used as commercial biocontrol agents against plant diseases. Recently, T. harzianum IOC-3844 (Th3844) and T. harzianum CBMAI-0179 (Th0179) demonstrated great potential in the enzymatic conversion of lignocellulose into fermentable sugars. Despite such potential, the genomes of both hydrolytic strains remain unclear. Herein, we performed whole-genome sequencing and assembly of Th3844 and Th0179 strains. To assess the genetic diversity within the genus Trichoderma, the results of both strains were compared with those from $T$. atroviride CBMAI-00020 (Ta0020) and T. reesei CBMAI-0711 (Tr0711). The resulting assembly revealed a total length of $40 \mathrm{Mb}$, (Th3844), $39 \mathrm{Mb}$ (Th0179), $36 \mathrm{Mb}$ (Ta0020), and $32 \mathrm{Mb}$ (Tr0711), in which 10,786 (Th3844), 11,322 (Th0179), 10,082 (Ta0020), and $8,796$ ( $\operatorname{Tr} 0711)$ genes were predicted. Then, the annotation of the predicted CDS sequences from the evaluated strain genes revealed 413 (Th3844), 413 (Th0179), 377 (Ta0020), and 329 (Tr0711) CAZymes. The orthology analysis revealed 18,349 orthogroups, which encompassed $95 \%$ of the total genes, 3,378 orthogroups with all species present, and 408 species-specific orthogroups. A genome- 
wide phylogenetic analysis modeled from the 1,864 single-copy orthogroups provided details on the relationship of the newly sequenced species with other Trichoderma and with more evolutionarily distant genera. Structural variants revealed genomic rearrangements between Th3844, Th0179, $\mathrm{Ta} 0020$, and Tr0711 with the T. reesei QM6a reference genome as well as the functional effects of such variants on the evaluated strains. In conclusion, the findings presented herein allow the genetic diversity of the evaluated strains, including those from the same species, to be viewed, offering opportunities to further explore such fungal genomes in future biotechnological and industrial applications.

\section{Introduction}

Fungi of the genus Trichoderma are characterized by their considerable nutritional versatility (Sharma et al., 2019), which allows them to be employed in a wide range of biotechnological applications (Kidwai and Nehra, 2017). For example, Trichoderma reesei is the primary fungal source of the industrial cellulases and hemicellulases present in enzymatic cocktails (Bischof et al., 2016). In addition to enzymatic activities, the capacity of biocontrol against plant pathogenic fungi has been widely explored in Trichoderma harzianum and Trichoderma atroviride (Medeiros et al., 2017; Saravanakumar et al., 2017). Recently, T. harzianum strains were explored for their enzymatic potential and were demonstrated to be useful for improving the lignocellulosic conversion into sugars during second-generation ethanol (2G ethanol) production (Almeida et al., 2021; Delabona et al., 2020a; Motta et al., 2021; Zhang et al., 2020a).

The phenotypic and ecological heterogeneity across fungi of the same genera is reflected, in part, by the diversity observed within their genomes (Priest et al., 2020). In this way, the diverse and important roles of fungi, as well as the technological advances in next-generation sequencing, have motivated broad efforts to sequence several fungal genomes (Ganesh Kumar et al., 2021; Hagestad et al., 2021; Nagel et al., 2021; Varga et al., 2019; Wu et al., 2018). Since the genome of T. reesei QM6a was first presented (Martinez et al., 2008), Trichoderma sequencing studies have increased with the goal of better understanding the biological and ecological roles of Trichoderma to improve their applications (Druzhinina et al., 2018b; Horta et al., 2014; Kubicek et al., 2011; Kubicek et al., 2019; Li et al., 2017; Schmoll et al., 2016). Such a growing number of sequenced species may help reveal the molecular basis for the specific features of diverse Trichoderma strains.

Previously, the transcriptional profiles of two T. harzianum strains, T. harzianum IOC-3844 (Th3844) and T. harzianum CBMAI-0179 (Th0179), were analyzed under cellulose degradation conditions and compared with those from $T$. atroviride CBMAI-0020 (Ta0020) and T. reesei CBMAI-0711 (Tr0711) (Almeida et al., 2021; Horta et al., 2018). Such studies have suggested the great potential of both $T$. harzianum strains as hydrolytic enzyme producers, and this was similar to Tr0711, while Ta0020 showed a low cellulolytic ability. Furthermore, differences in the transcription regulation within hydrolytic enzyme expression were observed for Th3844 and Th0179 (Rosolen et al., 2021), highlighting the genetic differences between such strains. Although previous studies investigated the Th3844 genomic regions, which are related to biomass degradation, through bacterial artificial chromosome (BAC) library construction (Crucello et al., 2015; Ferreira Filho et al., 2017), genomic information regarding the hydrolytic strains of $T$. harzianum, Th3844 and Th0179 remains unclear.

In this study, Pacific Biosciences (PacBio) (Ardui et al., 2018) technology was used to obtain highly contiguous de novo assemblies and to describe the genetic variation present among Th3844 and Th0179. Aiming to expand knowledge on the genetic diversity within the genus Trichoderma, the results obtained for $T$. harzianum strains were compared to those from $T$. atroviride and $T$. reesei. The 
83

84

85

86

87

88

89

90

91

92

93

94

95

96

97

98

99

100

101

102

103

104

105

106

107

108

109

110

111

112

113

114

115

116

117

118

119

120

121

122

123

124

chosen species are appropriate for the study's goal because while T. atroviride is a biocontrol species that is distantly related to the lignocellulolytic species T. reesei (Druzhinina et al., 2006), representing a well-defined phylogenetic species (Dodd et al., 2003), T. harzianum sensu lato is also commonly used in biocontrol but constitutes a complex of several cryptic species (Chaverri et al., 2015; Druzhinina et al., 2010).

After performing whole-genome annotation, we investigated the content of carbohydrate-active enzymes (CAZymes) (Cantarel et al., 2009) that were distributed among the studied genomes. To thoroughly investigate the genetic variability across the four evaluated strains, we explored the structural variants (SVs), which represent a major form of genetic and phenotypic variations that are inherited and polymorphic in species (Mills et al., 2011), between them and T. reesei QM6a, the reference genome (Martinez et al., 2008). In addition, by performing a comparative genomic analysis across the genus Trichoderma and more evolutionarily distant genera, the orthologs and the orthogroups across them were identified, and the rooted gene tree based on the single-copy orthologs was inferred.

The genomic resources we provide herein significantly extend our knowledge regarding the evolution and basic biology of the evaluated strains, and this may increase their biotechnological employment. The results from this study might also increase the availability of genomic data, which can be used to perform comparative studies to correlate phenotypic differences in the genetic diversity of Trichoderma species; therefore, the study may help to improve the search for enzymes with enhanced properties and provide aid toward improving the production of chemicals and enzymes in such fungi.

\section{$2 \quad$ Material and methods}

\subsection{Fungal strains and culture conditions}

The species originated from the Brazilian Collection of Environment and Industry Microorganisms (CBMAI), which is located in the Chemical, Biological, and Agricultural Pluridisciplinary Research Center (CPQBA) at the University of Campinas (UNICAMP), Brazil. The identity of Trichoderma isolates was authenticated by CBMAI based on phylogenetic studies of their internal transcribed spacer (ITS) region and translational elongation factor 1 (tefl) marker gene. Briefly, Th3844, Th0179, Ta0020, and Tr0711 strains were cultivated on potato dextrose agar (PDA) solid medium (ampicillin $100 \mu \mathrm{g} / \mathrm{ml}$ and chloramphenicol $34 \mu \mathrm{g} / \mathrm{ml}$ ) for 3 days at $28{ }^{\circ} \mathrm{C}$. Conidia were harvested, and an initial spore solution was used to inoculate $500 \mathrm{~mL}$ of potato dextrose broth (PDB) medium. The cultivation process was performed in biological triplicates for $72 \mathrm{~h}$ at $28{ }^{\circ} \mathrm{C}$ and $200 \mathrm{rpm}$ for all evaluated strains. Then, mycelial samples were harvested using Miracloth (Millipore), frozen using liquid nitrogen, and stored at $-80{ }^{\circ} \mathrm{C}$. Frozen material was used for DNA extraction.

\subsection{DNA extraction and sequencing}

The ground fungal tissue was suspended using lysis buffer, then phenol:chloroform:isoamyl alcohol (25:24:1) (Sigma, US) was added. After centrifugation at $4{ }^{\circ} \mathrm{C}$ and $13,000 \mathrm{rpm}$ for $10 \mathrm{~min}$, the aqueous layer was collected, and genomic DNA was precipitated via the addition of isopropanol. DNA was harvested by centrifugation at $4{ }^{\circ} \mathrm{C}$ and $13,000 \mathrm{rpm}$ for $10 \mathrm{~min}$, and the pellet was washed with $70 \%$ ethanol, followed by centrifugation at $4{ }^{\circ} \mathrm{C}$ and $13,000 \mathrm{rpm}$ for $5 \mathrm{~min}$. After a second washing with $95 \%$ ethanol and centrifugation at $4{ }^{\circ} \mathrm{C}$ and $13,000 \mathrm{rpm}$ for $5 \mathrm{~min}$, the pellet was dried at room temperature and dissolved in TE buffer. Before the quality control steps, the DNA was subjected to RNAse treatment. 
The quantity of the extracted gDNA was determined by measuring the absorbance at $260 \mathrm{~nm}$ using a NanoDrop 1000 spectrophotometer (Thermo Fisher Scientific) and Qubit Fluorometer (Thermo Fisher Scientific). The quality of extracted gDNA was assessed through $0.8 \%$ agarose gel electrophoresis. HiFi sequencing libraries were prepared according to the PacBio protocol, and sequencing was performed at the Arizona Genomics Institute (AGI; Tucson, USA) using a SMRT DNA sequencing system from PacBio (PacBio RSII platform).

\section{$131 \quad 2.3 \quad$ Genome assembly}

132 The data were transferred to a local server, and the genomes were assembled de novo using Canu software (v.2.1) (-pacbio - hifi, and a genome estimate equal to $40 \mathrm{Mb}$ for all evaluated strains), which was developed for long-read sequencing (Koren et al., 2017). Genome integrity was assessed using the Quality Assessment Tool (QUAST) (Gurevich et al., 2013) (v.5.0.2) and Benchmarking Universal Single-Copy Orthologs (BUSCO) (Simão et al., 2015) (v.4.1.4) tools. The Nucmer alignment tool from the MUMmer (v.4.0.0beta2) toolbox (Kurtz et al., 2004; Marçais et al., 2018) was used to perform the whole-genome alignments between the evaluated strains.

\subsection{Gene prediction and functional annotation}

140 Gene prediction was performed using AUGUSTUS (v.3.3.3) (Stanke et al., 2006) through gene models, which were built from T. harzianum T6776, T. atroviride IMI206040, and T. reesei QM6a (TrainAugustus (v.3.3.3)), together with the MAKER (Cantarel et al., 2008) (v.2.31.11). Such programs are implemented on the Galaxy platform. The predicted genes were functionally annotated by searching for homologous sequences in the UniProt (The UniProt, 2021), eggNOG-mapper v.2 (Cantalapiedra et al., 2021), and Protein Annotation with Z score (PANNZER2) (Törönen et al., 2018) databases. Transmembrane proteins were predicted using TMHMM v.2.0 (Krogh et al., 2001). For the annotation of CAZymes, we used CDS sequences as homology search queries against the database of the dbCAN2 server (Zhang et al., 2018), which integrates (I) DIAMOND (E-Value $<1 \mathrm{e}-$ 102) (Buchfink et al., 2015), (II) HMMER (E-Value < 1e-15, coverage > 0.35) (Finn et al., 2011), and Hotpep (Frequency > 2.6, Hits > 6) (Busk et al., 2017) tools. We considered all CDSs as true hits if they were predicted by at least two tools. Coverages were estimated with QualiMap

152 (Okonechnikov et al., 2016) (v.2.2.2c) using minimap2 (Li, 2018) v. 2.17 + galaxy4, which were both implemented on the Galaxy platform (Afgan et al., 2018).

\subsection{Ortholog identification and clustering}

The proteomes of Th3844, Th0179, Ta0020, and Tr0711 were compared with the Trichoderma spp. proteomes that are available on NCBI databases. Fusarium spp., Aspergillus spp., and Neurospora spp. were used as outgroup. For this analysis, we used the software OrthoFinder (Emms and Kelly, $2015,2019)$ v2.5.2, which clustered the protein sequences of fungi into orthologous groups and allowed the phylogenetic relationships between them to be identified. The consensus species tree was inferred using STAG algorithm (Emms and Kelly, 2018) and rooted using STRIDE algorithm (Emms and Kelly, 2017), which are implemented on the OrthoFinder program. The resulting tree from the OrthoFinder analysis was visualized and edited using Interactive Tree of Life (iTOL) v6 (Letunic and 163 Bork, 2007).

\section{$164 \quad 2.6$ Long-read structural variant analysis}

165 SVs were identified by aligning the PacBio HiFi reads from Th3844, Th0179, Ta0020, and Tr0711 166 with the T. reesei QM6a reference genome (Martinez et al., 2008) using the software Map with 
BWA-MEM (Li and Durbin, 2010) v.0.7.17.2 with (-x pacbio, sort by chromosomal coordinates). The duplicate reads in the BAM file were identified and marked using the tool MarkDuplicates (Institute) v.2.18.2.2. Variants were called using Sniffles (Sedlazeck et al., 2018) v.1.0.12+galaxy0 allowing for a minimum support of 10 (--min_support), maximum number of splits of 7 (-max_num_splits), maximum distance of 1000 (--max_distance), minimum length of 30 (-min_length), minimum mapping quality of 20 (--minmapping_qual), and CCS reads option (-ccs_reads). SVs were annotated using SnpEff (v.4.3+T. galaxy1) (Cingolani et al., 2012), which allowed the effects of variants in genome sequences to be categorized. Such tools are implemented on the Galaxy platform (Afgan et al., 2018).

\section{Results}

\section{7}

178

179

180

\subsection{Strain cultivations and evaluation of extracted DNA}

First, we cultivated Th3844, Th0179, Ta0020, and Tr0711, which can be identified by common morphological characteristics, such as a bright green conidial pigment and a repetitive branch (Figure 1). Next, the DNA from the evaluated Trichoderma isolates was extracted, and its integrity and quality were assessed (Supplementary Material 1: Supplementary Table 1 and Supplementary Material 1: Supplementary Figure 1).

\subsection{Assembled genomic features and general comparison across Trichoderma spp.}

In the present study, we introduced the whole-genome sequences of Th3844, Th0179, Ta0020, and Tr0711 (Table 1). Overall, the genomes of the evaluated Trichoderma spp. varied in a number of contigs (14-26), sizes (32-40 Mb) and gene contents (8,796-11,322 genes). In comparison with the other strains, Th0711 contains the smallest gene repertoire, while Th3844 contains the highest gene repertoire. To assess the completeness and integrity of the assembled genomes, BUSCO analysis was performed. For all evaluated strains, over $90 \%$ of genes were complete. Although the genome of Th3844 presented a considerable number of missing genes (9.7\%), its assembled genome exhibited a lower degree of fragmentation compared to that of other genomes.

Considering the genome sequencing coverage, genome size, GC content, length metrics (N50 and L50 values), assembly level, and number of genes, the genomes of Th3844, Th0179, Ta0020, and Tr0711 were compared to other fungal genome references (Baroncelli et al., 2015; Chung et al., 2021; Kubicek et al., 2011; Li et al., 2017; Martinez et al., 2008) (Table 2). All T. harzianum genomes were similar in size and GC content. The same profile was observed for the T. atroviride and $T$. reesei genomes. Large differences were found for the genome sequencing coverage, in which Th3844, Th0179, Ta0020, and Tr0711 presented higher values than those reported for other strains in the literature (Baroncelli et al.; Kubicek et al., 2011; Li et al., 2017). In regard to quality, except for $\operatorname{Tr} 0711$, the genomes assembled in this study showed a lower degree of fragmentation compared to those previously available (Baroncelli et al., 2015; Chung et al., 2021; Kubicek et al., 2011; Li et al., 2017; Martinez et al., 2008).

We also performed alignment analyses to evaluate the similarities and variations between the genomes of the studied strains (I) with T. reesei QM6a, which is a model organism for the lignocellulose deconstruction system and has a genome that is assembled at the chromosomic level (Li et al., 2017) (Figure 2), and (II) with their respective reference genomes (Supplementary Material 1: Supplementary Figure 2). The profile of alignment across the genomes illustrated the degree of divergence across the studied strains with $T$. reesei QM6a and with the closest related strain of each evaluated fungus. For each evaluated strain, we observed alignment in different regions of the $T$. reesei QM6a reference 
genome. Using T. reesei QM6a as a reference genome, we found a total of (I) $12 \%$ aligned bases for Th3844, (II) 13\% aligned bases for Th0179, (III) 8\% aligned bases for Ta0020, and (IV) 95\% aligned bases for Tr0711. The total percentage of aligned bases for Th3844 and Th0179 genomes with the $T$. harzianum T6776 genome was approximately $83.5 \%$ and 89\%, respectively. In addition, for the $\mathrm{Ta} 0020$ genome, the total percentage of aligned bases to the T. atroviride IMI 206040 reference genome was approximately $88 \%$.

\subsection{Genome functional annotation and CAZyme distribution}

217

After performing the genome assembly and gene prediction steps, functional annotation was

218

219 accomplished by a homology search. The functional category distribution regarding the clusters of orthologous groups of proteins (COG) (Tatusov et al., 2000) is shown in Figure 3 and Supplementary Material 1: Supplementary Table 2. Disregarding the (S) function unknown category, the top 5 functional categories were $(\mathrm{G})$ carbohydrate metabolism and transport, $(\mathrm{O})$ posttranslational modification, protein turnover, chaperone functions, $(\mathrm{Q})$ secondary structure, $(\mathrm{E})$ amino acid transport and metabolism, and (U) intracellular trafficking, secretion, and vesicular transport. Overall, the evaluated strains seem to have similar COG assignment profiles. The complete functional annotation of the four genomes is available in Supplementary Material 2: Supplementary Table 3.

Within filamentous fungi, the genus Trichoderma is a model system for the production of CAZymes, which includes glycoside hydrolases (GHs), carbohydrate esterases (CEs), glycosyltransferases (GTs), polysaccharide lyases (PLs), auxiliary activities (AAs), and carbohydrate-binding modules (CBMs) (Cantarel et al., 2009). Due to the important role of CAZymes in microparasitism and saprophytic degradation of debris, a thorough investigation regarding the enzyme content in the genomes of the four Trichoderma spp. was performed (Supplementary Material 3: Supplementary Table 4). Overall, the genes encoding the CAZymes encompassed approximately $3.8 \%$ of the genomes assembled herein. Moreover, to detect similarities and differences between the strains, their CAZyme profiles were compared (Figure 4A).

Among the main CAZyme classes detected in all strains, GHs were overrepresented, and Th3844 (256) and Th0179 (252) had the highest number, followed by Ta0020 (230) and Tr0711 (184). This CAZyme class was followed by GTs as follows: (I) 88 (Th3844), (II) 90 (Th0179), (III) 90 (Ta0020), and (IV) 86 (Tr0711). However, when the CAZymes with predicted signal peptides were analyzed, we observed that only a few GTs were secreted, as follows: (I) 8 (Th3844), (II) 9 (Th0179), (III) 7 (Ta0020), and (IV) 4 (Tr0711) (Figure 4B). The distribution of the different CAZyme families among strains was investigated and is available in Supplementary Material 1: Supplementary Figure 3. For simplification purposes, only the CAZyme families related to biomass degradation are exhibited in Figure 5. Overall, CAZymes from the GH5, AA1, AA3, GH2, and GH3 families were well represented for all strains, and the highest numbers were in Th3844 and Th0179. involved in such activity were also identified in the four evaluated genomes (Supplementary Material 1: Supplementary Figure 3). For example, CAZymes from the GH18 family, which are related to chitin degradation, were present in all evaluated strains, and CAZymes from GH75 are related to chitosan degradation. Additionally, we would like to highlight that other CAZyme classes, including GH16, GH55, and GH64, are related to the mycoparasitic interaction that was present in the genomes of Th3844, Th0179, Ta0020, and Tr0711.

\subsection{Orthology analysis, phylogenetic profiling, and structural variant analyses}


254

255

256

257

258

259

260

261

262

263

264

265

266

267

268

269

270

271

272

273

274

275

276

277

278

279

280

281

282

283

284

285

286

287

288

289

290

291

292

293

294

295

296

297

298

299
The predicted proteomes of Th3844, Th0179, Ta0020, and Tr0711 were compared with those of 19 other Trichoderma spp. and with those from more phylogenetically distant fungi, including Fusarium spp., Aspergillus spp., and Neurospora spp. (outgroups) (Supplementary Material 4: Supplementary Table 5). We identified a total of 18,349 orthogroups, which encompassed 313,444 genes (95\%) in a total of 329,927 genes, i.e., the number of unassigned genes was equal to $16,483(5 \%)$ genes. Moreover, we detected 3,378 orthogroups with all species present, of which 1,864 consisted entirely of single-copy genes and 408 species-specific orthogroups. Fifty percent of all genes were in orthogroups with 29 or more genes (G50 was 29) and were contained in the largest 4,609 orthogroups (O50 was 4609). Regarding the orthologous relationships across the evaluated strains, both $T$. harzianum strains shared the highest number of orthologous genes among them compared to that of the other strains. In relation to the other evaluated strains, Th3844 and Th0179 presented more orthologs that were in common with Ta0020 than with Tr0711 (Table 3). To explore the evolutionary history of Th3844, Th0179, Ta0020, and Tr0711, a rooted species tree was inferred using the 1,864 single-copy orthologous genes that were conserved in the 29 fungi analyzed (Figure 6 and Supplementary Material 1: Supplementary Figure 4). Such phylogenetic analysis indicated that Tr0711 was most closely related to Trichoderma parareesei CBS 125925 , while Ta0020 was most closely related to T. atroviride IMI206040. On the other hand, Th0179 and Th3844 were phylogenetically close to Trichoderma lentiforme CFAM-422 and to other T. harzianum strains (TR274 and CB226.95), respectively.

The SVs of the evaluated Trichoderma isolates were identified by mapping the long reads of the fungi against the reference genome of $T$. reesei QM6a (Martinez et al., 2008). A total of 12,407 (Th3844), 12,763 (Th0179), 11,650 (Ta0020), and 7,103 ( $\operatorname{Tr} 0711)$ SVs were identified for each strain, showing substitution rates of $\sim 1 / 2,674$ nucleotides (Th3844), 1/2,585 nucleotides (Th0179), $\sim 1 / 2,832$ nucleotides (Ta0020), and $\sim 1 / 4,655$ nucleotides ( $\operatorname{Tr} 0711$ ). These SVs included different phenomena that affect gene sequences, such as break ends, deletions, multiple nucleotides and InDels, duplications, insertions, and inversions (Supplementary Material 5: Supplementary Table 6 and Figure 7A). Compared with the other evaluated strains, Tr0711 presented a low number of SVs, while Th0179 displayed the highest number. For all evaluated strains, the most presented SV categories were multiple nucleotides and an InDel, followed by deletions and insertions (Figure 7A). To thoroughly investigate the functional effects of the identified SVs, we performed an annotation of the structural rearrangements, which were placed into different classes based on their predicted effects on protein function. Details of these effects can be found in Supplementary Material 6: Supplementary Table 7, and the most prevalent effects are represented in Figure 7B. For all evaluated strains, the majority of variants presented a modifier impact, which was higher at downstream and upstream genomic locations. Such an effect was more accentuated for both T. harzianum strains. In addition, SVs present in transcripts, genes, and intergenic regions were well represented for Ta0020.

\section{Discussion}

Diversity within the genus Trichoderma is evident from the wide range of phenotypes exhibited by the fungi as well as the various ecological roles and industrial purposes the fungi serve (Nakkeeran et al., 2021). Because of their various applications, different Trichoderma species have become model organisms for a broad spectrum of physiological phenomena, such as plant cell wall degradation and enzyme production (Fang et al., 2021), biocontrol (Zin and Badaluddin, 2020), and response to light (Schmoll, 2018). Within the genus Trichoderma, T. harzianum has been used as a commercial biocontrol agent against plant diseases (Fraceto et al., 2018). In addition to their mycoparasitic activities, hydrolytic enzymes from T. harzianum strains have demonstrated great potential in the conversion of lignocellulosic biomass into fermentable sugars (Almeida et al., 2021; Delabona et al., 
2020b; Motta et al., 2021; Zhang et al., 2020b). Recently, different types of enzymatic profiles across Trichoderma species were reported, in which Th3844 and Th0179 presented a higher hydrolytic potential during growth on cellulose than that of Ta0020 (Almeida et al., 2021); furthermore, differences between Th3844 and Th0179 concerning the transcriptional regulation coordinated by XYR1 and CRE1 during cellulose degradation were reported (Rosolen et al., 2021). Because such diversity in enzyme response might be related to transcriptomic and genomic differences, we aimed to provide foundations for further studies that could investigate such variations at a genomic level.

Technological advances, particularly in long-read sequencing, coupled with the increasing efficiency and decreasing costs across sequencing platforms, enabled fungal genomes to be characterized (Dal Molin et al., 2018; Miyauchi et al., 2020; Wu et al., 2020). Herein, we presented high-quality genome assemblies for two T. harzianum strains with hydrolytic potential (Th3844 and Th0179) and, for comparative purposes, for a mycoparasitic species (Ta0020) and saprotrophic species (Tr0711). Thus, $T$. reese $i$ and $T$. atroviride strains were used to assess the genetic differences in the genus Trichoderma. With the aim of obtaining high-quality genomes, we employed Canu software for the genome assemblies, and this software has been applied with success in the assembly of fungal genomes (Courtine et al., 2020; Gan et al., 2020; Montoliu-Nerin et al., 2020). Except for Tr0711, the resulting genomics assemblies displayed the highest coverage scores and the lowest fragmentation values compared to those of Trichoderma virens Gv29-8 (Kubicek et al., 2011) as well as to T. harzianum T6776 (Baroncelli et al., 2015) and T. atroviride IMI206040 (Kubicek et al., 2011), which were used as the reference genome in preceding studies from our research group (Almeida et al., 2021; Horta et al., 2018). Although the genomes were not assembled at the chromosome level, the quality of the Th3844, Th0179, Ta0020, and Tr0711 genome assemblies based on the BUSCO value was over $90 \%$. Only the Th3844 genome exhibited $9.7 \%$ missing genes. However, even chromosome-level genome assembly does not necessarily achieve a complete BUSCO score (Chung et al., 2021). This may be because the assembly is not $100 \%$ accurate, but at the same time, the BUSCO value may not be a perfect indicator to assess genomic qualities. Despite its limitations, without a definitive alternative, BUSCO is still an essential genomic quality assessment tool that includes up-to-date data from many species.

After evaluating the quality of the four assembled genomes, we performed a gene prediction and functional annotation for the datasets. The ecological behavior of the mycoparasites $T$. atroviride and T. virens, compared to the plant wall degrader T. reesei, is reflected by the sizes of the respective genomes; T. atroviride (36 Mb) and T. virens (39 Mb) were somewhat larger than the weakly mycoparasitic T. reesei (33 Mb) (Kubicek et al., 2011; Martinez et al., 2008). Herein, compared to Th3844 (40 Mb), Th0179 (39 Mb), and Ta0020 (36 Mb), the genome of Tr0711 (32 Mb) was smaller, which might be conceivably as the gene function is lost to mycoparasitism during the evolution of $T$. reesei (Kubicek et al., 2011). In relation to the number of genes, our results showed that Tr0711 presented a smaller gene content than that of Th3844, Th0179, and Ta0020. Such findings corroborated a previous study (Xie et al., 2014), in which 9,143 and 11,865 genes were predicted for $T$. reese $i$ and $T$. atroviride, respectively. In relation to the T. reesei QM6a reference genome, the genomes of Th3844, Th0179, Ta0020, and Tr0711 displayed significant structural reorganization, which was more greatly accentuated by an increased phylogenetic distance. Interestingly, this structural reorganization was also observed within strains of the same species, 342 highlighting their genetic diversity.

\section{$343 \quad 4.1 \quad$ Comparative and functional genomics}


To obtain insights regarding the functional profile of Th3844, Th0179, Ta0020, and Tr0711, COG analyses of proteins from their genomes were performed. "Carbohydrate metabolism and transport" was a notable COG term for all evaluated strains, suggesting that the genomic arsenal of these fungi is connected to their ability of using carbon sources that are available in the environment. Such characteristics are well known for saprophytic fungal T. reesei (Arntzen et al., 2020), and recent studies have observed the same characteristics for T. harzianum (Almeida et al., 2021; Delabona et al., 2020a). "Posttranslational modification, protein turnover, chaperone functions" was the second most notable COG term that was present in the four evaluated genomes. Posttranslational modifications (PTMs), which are used by eukaryotic cells to diversify their protein functions and dynamically coordinate their signaling networks, encompass several specific chemical changes that occur on proteins following their synthesis (Ramazi and Zahiri, 2021). The production of intact and functional proteins is a prerequisite for large-scale protein production, and extensive host-specific PTMs often affect the catalytic properties and stability of recombinant enzymes. The high extracellular secretion capability and eukaryotic PTM machinery make Trichoderma spp. particularly interesting hosts (Wei et al., 2021). In this context, PTMs are a major factor in the cellulolytic performance of fungal cellulases (Amore et al., 2017; Beckham et al., 2012; Dana et al., 2014), and the impact of plant PTMs on the enzyme performance and stability of the major cellobiohydrolase Cel7A from $T$. reesei has already been determined (van Eerde et al., 2020). In addition, PTMs, especially phosphorylation, of the proteins involved in plant biomass degradation, including CRE1, play an essential role in signal transduction to achieve carbon catabolite repression (CCR) (Han et al., 2020; Horta et al., 2019). Thus, describing this class of Trichoderma genomes is essential to understand the impact of alternative PTMs on the catalytic performance and stability of recombinant enzymes. We also would like to highlight that the "secondary structure" and "amino acid transport and metabolism", which are related to PTMs, were overrepresented COG terms.

To achieve the complete depolymerization of complex lignocellulosic polysaccharides, a repertoire of enzymes that act together on different chemical bonds is needed (Chukwuma et al., 2020). The comparative genomics of Trichoderma spp. suggested that mycoparasitic strains, such as $T$. vires and T. atroviride, presented a set of genes, including CAZymes and genes encoding secondary metabolites, that were more expressive and related to mycoparasitism compared to those of the saprotrophic species T. reesei (Kubicek et al., 2011). Although such fungi are widely used in industry as a source of cellulases and hemicellulases, they have a smaller arsenal of genes that encode the CAZymes related to biomass deconstruction than that of other lignocellulolytic fungi (Martinez et al., 2008). A potential reason for this observation is that its CAZyme content was shaped by loss and a massive horizontal gene transfer (HGT) was gained in enzymes that degrade plant cell walls (Druzhinina et al., 2018a). Herein, compared to the other evaluated strains, Tr0711 also displayed a lower quantity of genes that encode CAZymes. Although the genome of the evaluated strains presented a significant number of GTs, only a few were predicted to be secreted proteins. Such a result could be related to the enzyme activity exhibited by the CAZymes from the GT class, which includes enzymes that are involved in cell wall synthesis in microorganisms and not necessarily in lignocellulose deconstruction (Ardèvol and Rovira, 2015). Furthermore, the presence of putative CAZyme-encoding genes in the genomes of Th0179 and Th3844 provides insight into its lignocellulose-degrading enzyme potential but cannot be directly related to its real degradation ability. In fact, since fungal species rely on different strategies, it has been observed that the number of genes related to the degradation of a given polysaccharide is not necessarily correlated to the extent of its degradation (Arntzen et al., 2020; Kjærbølling et al., 2020). For instance, T. reesei relies on the high production levels of a limited set of glycosyl hydrolases (Arntzen et al., 2020). For this 390 reason, CAZy analysis is associated with functional approaches, such as enzymatic activity assays, 391 which provide valuable insight into the actual behavior of the concerned species on specific 
392

393

394

395

396

397

398

399

400

401

402

403

404

405

406

407

408

409

410

411

412

413

414

415

416

417

418

419

420

422

423

424

425

426

427

428

429

430

431

432

433

434

435

436

437

lignocellulose substrates. Regarding the CAZyme content, the results found here for the Th3844, Th0179, Ta0020, and Tr0711 genomes follow the same profile as that of a previous study (Fanelli et al., 2018), in which the CAZyme genetic endowment of some strains from T. harzianum, including B97 and T6776, was significantly higher than that of T. atroviride IMI206040, T. reesei QM6a, and T. virens $\mathrm{Gv}-29-8$.

In relation to the CAZyme families that are directly associated to the deconstruction of plant biomass, the genomes of Th3844, Th0179, Ta0020, and Tr0711 showed an expressive number of genes encoding GH5, which includes cellulases that are most abundant in fungi (Li and Walton, 2017) and are commonly present in industrial enzymatic cocktails; GH3, which includes $\beta$-glucosidases that are frequently secreted into the medium (Guo et al., 2016); and AA3, which is a member of the enzyme arsenal that is auxiliary to GHs (Levasseur et al., 2013). Lytic polysaccharide monooxygenases (LPMOs), which are classified into CAZy auxiliary activity families AA9-AA11 and AA13-AA16, are copper-dependent enzymes that also perform important roles in lignocellulose degradation (Couturier et al., 2018; Monclaro and Filho, 2017). As AA9, AA11, AA13, AA14, and AA16 are exclusive to fungal genomes, multiple genes encoding LPMOs appear to be common in fungal genomes, particularly in Ascomycetes and Basidiomycetes (Kracher et al., 2016). Herein, each of the Th3844, Th0179, Ta0020, and Tr0711 genomes exhibited three AA9 and two AA14 enzymes. Compared to other fungi, the genomes of Trichoderma species harbor a high number of chitinolytic genes (Kubicek et al., 2011; Kubicek et al., 2019), reflecting the importance of these enzymes in the mycoparasitic characteristic of fungi. From the Trichoderma genomes that were analyzed in detail thus far, the fungal chitinases that belong to the family GH 18 are significantly expanded in $T$. virens, T. atroviride, T. harzianum, Trichoderma asperellum, Trichoderma gamsii, and Trichoderma atrobrunneum (Fanelli et al., 2018; Kubicek et al., 2011). Similarly, the number of chitosanases (GH75) is enhanced and there are at least five corresponding genes; in contrast, most other fungi have only one or two corresponding genes (Kappel et al., 2020; Kubicek et al., 2011). Furthermore, $\beta$-1,3-glucanases that belong to GH families $16,17,55,64$, and 81 are expanded in Trichoderma mycoparasites compared to other fungi (Fanelli et al., 2018; Kubicek et al., 2011). Here, the CAZyme families that are related to mycoparasitic activity were present in the four genomes studied, and the most were in Th3844 and Th0179.

\subsection{Insights into the evolutionary history}

Comparative genomics could be a powerful tool for studying fungal evolution and promoting insights into their genetic diversity. In this context, identifying orthology relationships among sequences is an essential step to more thoroughly understand the genetic correlation of particular fungi. Thus, by applying orthology analyses, we could identify orthogroups and orthologs between the evaluated strains, as well as among some other Trichoderma spp. and filamentous fungi that are more genetically distant. In the genus Trichoderma, several lifestyles have been documented, including saprotrophy, which is a lifestyle that is also observed in other filamentous fungi, such as Neurospora spp., Aspergillus spp., and Fusarium spp. (Arntzen et al., 2020; Corrêa et al., 2020; Najjarzadeh et al., 2021). Thus, the proteomes of some species and strains of such genera were also included in the orthology analysis. Through our results, we may infer that some genus-specific genes are necessary for specific lifestyles and are shared by fungi that have the same lifestyle but are in quite different evolutionary orders. The phylogenetic tree modeled from the orthologous analysis revealed a low bootstrap value for the clade formed by aligning the sequence proteomes from T. harzianum. Furthermore, the presence of other Trichoderma species, such as T. lentiforme, T. guizhouense, and T. simmonsii, was observed. These observations might be explained by the complex speciation process within the $T$. harzianum species group (Druzhinina et al., 2010); therefore, the phylogenetic 
438

439

440

441

442

443

444

445

446

447

448

449

450

451

452

453

454

455

456

457

458

459

460

461

462

463

464

465

466

467

468

469

470

471

472

473

474

475

476

477

478

479 position is uncertain for fungi from these species. However, the molecular identification of Th3844 and Th0179 based on the ITS and tefl sequences has already been reported (Rosolen et al., 2021), confirming that both strains were phylogenetically close to other T. harzianum strains. Tr0711 was grouped with $T$. pararessei CBS 125925 , and both were phylogenetically in proximity to other $T$. reesei strains.

While short reads perform well in the identification of single nucleotide variants (SNVs) and small insertions and deletions (InDels), they are not well suited for detecting changes in larger sequences (Mahmoud et al., 2019). SVs, which include insertions, deletions, duplications, inversions, or translocations that affect $\geq 50$ bp (Mills et al., 2011), are more amenable to long-read sequencing (Mitsuhashi and Matsumoto, 2020; Sakamoto et al., 2020). In fungi, SV analysis was employed successfully using reads from third-generation sequencing (Badet et al., 2021; Basile et al., 2021). In this study, we detected SVs by aligning our four genomes against T. reesei QM6a (Martinez et al., 2008); although the genomes were assembled at a scaffolding level, unlike the T. reesei QM6a reference genome that was assembled at the chromosome level, we chose to proceed with this dataset because its annotation file was available ( $\mathrm{Li}$ et al., 2017). As expected, due to phylogenetic proximity to the reference genome (Rosolen et al., 2021), Tr0711 showed the lowest number of SVs compared to that of the other strains. However, although T. atroviride is phylogenetically distant from T. reesei (Rosolen et al., 2021), Ta0020 exhibited fewer SVs than that of both T. harzianum strains, and this result might be explained by the uncertain phylogenetic position of fungi in these species (Druzhinina et al., 2010). Although the T. harzianum strains are phylogenetically close (Rosolen et al., 2021), genetic variability across the strains is evident when comparing the SVs that were identified from mapping both genomes against T. reesei QM6a (Martinez et al., 2008). Such results are consistent with the findings of previous studies in that genetic variations between fungal strains of the same species are not uncommon (Andersen et al., 2011; de Vries et al., 2017; Thanh et al., 2019).

Considering their basic and economic importance, the high-quality genomes found herein might be helpful for better understanding the diversity within the genus Trichoderma, as well as improving the biotechnological applications of such fungi. Furthermore, the comparative study of multiple related genomes might be helpful for understanding the evolution of genes that are related to economically important enzymes and for clarifying the evolutionary relationships related to protein function.

\section{Conflicts of interest}

The authors declare that the research was conducted in the absence of any commercial or financial relationships that could be construed as potential conflicts of interest.

\section{Author contributions}

RRR: Writing - original draft, methodology, formal analysis, and visualization. MACH: Conceptualization, methodology, and writing - review \& editing. PHCA: Methodology and resources. CCS: Methodology and formal analysis. DAS: Methodology and resources. GHG: Writing - review \& editing. APS: Conceptualization, supervision, review \& editing, and funding acquisition.

\section{Funding}

Financial support for this work was provided by the São Paulo Research Foundation (FAPESP Process number 2015/09202-0 and 2018/19660-4), the Coordination of Improvement of Higher Education Personnel (CAPES, Computational Biology Program - Process number 
88882.160095/2013-01), and the Brazilian National Council for Technological and Scientific Development (CNPq- Process number 312777/2018-3). RRR received a PhD fellowship from CAPES (88887.482201/2020-00) and FAPESP (2020/13420-1), PHCA received a PhD fellowship

483 from CAPES (88887.612254/2021-00), MACH received a postdoctoral fellowship from FAPESP

484 (2020/10536-9), and APS received a research fellowship from CNPq (312777/2018-3).

\section{Abbreviations}

486 2G ethanol: second-generation ethanol

487 BAC: bacterial artificial chromosome

488 BUSCO: benchmarking universal single-copy orthologs

489 CAZymes: carbohydrate-active enzymes

490 CBMs: carbohydrate-binding modules

491 CBMAI: Brazilian collection of environmental and industrial microorganisms

492 CCR: carbon catabolite repression

493 CEs: carbohydrate esterases

494 COG: clusters of orthologous groups of proteins

495 CPQBA: chemical, biological, and agricultural pluridisciplinary research center

496 GHs: glycoside hydrolases

497 GTs: glycosyltransferases

498 HGT: horizontal gene transfer

499 InDels: small insertion and deletions

500 iTOL: interactive tree of life

501 ITS: internal transcribed spacer

502 LPMOs: lytic polysaccharide mono-oxygenases

503 PacBio: pacific biosciences

504 PANNZER2: protein annotation with z score

505 PDA: potato dextrose agar

506 PDB: potato dextrose broth

507 PLs: polysaccharide lyases

508 PTMs: posttranslational modifications

509 QUAST: quality assessment tool

510 SNVs: single nucleotide variants

511 SVs: structural variants

512 Ta0020: Trichoderma atroviride CBMAI-0020

513 tef1: translational elongation factor 1

514 Th0179: Trichoderma harzianum CBMAI-0179

515 Th3844: Trichoderma harzianum IOC-3844

\section{Acknowledgments}

517 We are grateful to CBMAI Campinas and SP for conceiving the fungal isolates used in the current 518 study; the Center of Molecular Biology and Genetic Engineering (CBMEG) at the University of

519 Campinas and SP for the use of the center and laboratory space; and the São Paulo Research 520 Foundation (FAPESP), the Coordination of Improvement of Higher Education Personnel (CAPES, 521 Computational Biology Program), and the Brazilian National Council for Technological and

522 Scientific Development (CNPq) for supporting the project and researchers. 


\section{Data availability statement}

524

525

526

527

528

All data generated or analyzed in this study are included in this published article (and its supplementary information files). The raw datasets and the assembled genomes were deposited in the NCBI Sequence Read Archive and can be accessed under BioProject number PRJNA781962 and BioSample number, as follow SAMN23309297 (Th3844), SAMN23309298 (Th0179), SAMN23309299 (Ta0020), and SAMN23309300 (Tr0711).

\section{References}

Afgan, E., Baker, D., Batut, B., van den Beek, M., Bouvier, D., Čech, M., Chilton, J., Clements, D., Coraor, N., Grüning, B.A., Guerler, A., Hillman-Jackson, J., Hiltemann, S., Jalili, V., Rasche, H., Soranzo, N., Goecks, J., Taylor, J., Nekrutenko, A., Blankenberg, D., 2018. The Galaxy platform for accessible, reproducible and collaborative biomedical analyses: 2018 update. Nucleic Acids Research 46, W537-W544. https://doi.org/10.1093/nar/gky379.

Almeida, D.A., Horta, M.A.C., Ferreira Filho, J.A., Murad, N.F., de Souza, A.P., 2021. The synergistic actions of hydrolytic genes reveal the mechanism of Trichoderma harzianum for cellulose degradation. Journal of Biotechnology 334, 1-10. https://doi.org/https://doi.org/10.1016/j.jbiotec.2021.05.001.

Amore, A., Knott, B.C., Supekar, N.T., Shajahan, A., Azadi, P., Zhao, P., Wells, L., Linger, J.G., Hobdey, S.E., Vander Wall, T.A., Shollenberger, T., Yarbrough, J.M., Tan, Z., Crowley, M.F., Himmel, M.E., Decker, S.R., Beckham, G.T., Taylor, L.E., 2nd, 2017. Distinct roles of $\mathrm{N}$ - and O-glycans in cellulase activity and stability. Proceedings of the National Academy of Sciences of the United States of America 114, 13667-13672. https://doi.org/10.1073/pnas.1714249114.

Andersen, M.R., Salazar, M.P., Schaap, P.J., van de Vondervoort, P.J.I., Culley, D., Thykaer, J., Frisvad, J.C., Nielsen, K.F., Albang, R., Albermann, K., Berka, R.M., Braus, G.H., BrausStromeyer, S.A., Corrochano, L.M., Dai, Z., van Dijck, P.W.M., Hofmann, G., Lasure, L.L., Magnuson, J.K., Menke, H., Meijer, M., Meijer, S.L., Nielsen, J.B., Nielsen, M.L., van Ooyen, A.J.J., Pel, H.J., Poulsen, L., Samson, R.A., Stam, H., Tsang, A., van den Brink, J.M., Atkins, A., Aerts, A., Shapiro, H., Pangilinan, J., Salamov, A., Lou, Y., Lindquist, E., Lucas, S., Grimwood, J., Grigoriev, I.V., Kubicek, C.P., Martinez, D., van Peij, N.N.M.E., Roubos, J.A., Nielsen, J., Baker, S.E., 2011. Comparative genomics of citric-acid-producing Aspergillus niger ATCC 1015 versus enzyme-producing CBS 513.88. Genome research 21, 885-897. https://doi.org/10.1101/gr.112169.110.

Ardèvol, A., Rovira, C., 2015. Reaction Mechanisms in Carbohydrate-Active Enzymes: Glycoside Hydrolases and Glycosyltransferases. Insights from ab Initio Quantum Mechanics/Molecular Mechanics Dynamic Simulations. Journal of the American Chemical Society 137, 7528-7547. https://doi.org/10.1021/jacs.5b01156.

Ardui, S., Ameur, A., Vermeesch, J.R., Hestand, M.S., 2018. Single molecule real-time (SMRT) sequencing comes of age: applications and utilities for medical diagnostics. Nucleic Acids Research 46, 2159-2168. https://doi.org/10.1093/nar/gky066. 
562

563

564

565

566

567

568

569

570

571

572

573

574

575

576

577

578

579

580

581

582

583

584

585

586

587

588

589

590

591

592

593

594

595

596

597

598

Arntzen, M.Ø., Bengtsson, O., Várnai, A., Delogu, F., Mathiesen, G., Eijsink, V.G.H., 2020. Quantitative comparison of the biomass-degrading enzyme repertoires of five filamentous fungi. Scientific Reports 10, 20267. https://doi.org/10.1038/s41598-020-75217-z.

Badet, T., Fouché, S., Hartmann, F.E., Zala, M., Croll, D., 2021. Machine-learning predicts genomic determinants of meiosis-driven structural variation in a eukaryotic pathogen. Nature Communications 12, 3551. https://doi.org/10.1038/s41467-021-23862-x.

Baroncelli, R., Piaggeschi, G., Fiorini, L., Bertolini, E., Zapparata, A., Pè Mario, E., Sarrocco, S., Vannacci, G., Draft Whole-Genome Sequence of the Biocontrol Agent Trichoderma harzianum T6776. Genome Announcements 3, e00647-00615. https://doi.org/10.1128/genomeA.00647-15.

Baroncelli, R., Piaggeschi, G., Fiorini, L., Bertolini, E., Zapparata, A., Pè, M.E., Sarrocco, S., Vannacci, G., 2015. Draft Whole-Genome Sequence of the Biocontrol Agent Trichoderma harzianum T6776. Genome announcements 3, e00647-00615. https://doi.org/10.1128/genomeA.00647-15.

Basile, A., De Pascale, F., Bianca, F., Rossi, A., Frizzarin, M., De Bernardini, N., Bosaro, M., Baldisseri, A., Antoniali, P., Lopreiato, R., Treu, L., Campanaro, S., 2021. Large-scale sequencing and comparative analysis of oenological Saccharomyces cerevisiae strains supported by nanopore refinement of key genomes. Food Microbiology 97, 103753. https://doi.org/https://doi.org/10.1016/j.fm.2021.103753.

Beckham, G.T., Dai, Z., Matthews, J.F., Momany, M., Payne, C.M., Adney, W.S., Baker, S.E., Himmel, M.E., 2012. Harnessing glycosylation to improve cellulase activity. Current Opinion in Biotechnology 23, 338-345. https://doi.org/https://doi.org/10.1016/j.copbio.2011.11.030.

Bischof, R.H., Ramoni, J., Seiboth, B., 2016. Cellulases and beyond: the first 70 years of the enzyme producer Trichoderma reesei. Microb. Cell Fact. 15, 106. https://doi.org/10.1186/s12934-0160507-6.

Buchfink, B., Xie, C., Huson, D.H., 2015. Fast and sensitive protein alignment using DIAMOND. Nature Methods 12, 59-60. https://doi.org/10.1038/nmeth.3176.

Busk, P.K., Pilgaard, B., Lezyk, M.J., Meyer, A.S., Lange, L., 2017. Homology to peptide pattern for annotation of carbohydrate-active enzymes and prediction of function. BMC bioinformatics 18, 214-214. https://doi.org/10.1186/s12859-017-1625-9.

Cantalapiedra, C.P., Hernández-Plaza, A., Letunic, I., Bork, P., Huerta-Cepas, J., 2021. eggNOGmapper v2: Functional Annotation, Orthology Assignments, and Domain Prediction at the Metagenomic Scale. bioRxiv 2021.2006.2003.446934. https://doi.org/10.1101/2021.06.03.446934.

Cantarel, B.L., Coutinho, P.M., Rancurel, C., Bernard, T., Lombard, V., Henrissat, B., 2009. The Carbohydrate-Active EnZymes database (CAZy): an expert resource for Glycogenomics. Nucleic acids research 37, D233-D238. https://doi.org/10.1093/nar/gkn663. 
599

600

601

602

603

604

605

606

607

608

609

610

611

612

613

614

615

616

617

618

619

620

621

622

623

624

625

626

627

628

629

630

631

632

633

634

635

636

637

Cantarel, B.L., Korf, I., Robb, S.M.C., Parra, G., Ross, E., Moore, B., Holt, C., Sánchez Alvarado, A., Yandell, M., 2008. MAKER: an easy-to-use annotation pipeline designed for emerging model organism genomes. Genome research 18, 188-196. https://doi.org/10.1101/gr.6743907.

Chaverri, P., Branco-Rocha, F., Jaklitsch, W., Gazis, R., Degenkolb, T., Samuels, G.J., 2015. Systematics of the Trichoderma harzianum species complex and the re-identification of commercial biocontrol strains. Mycologia 107, 558-590. https://doi.org/10.3852/14-147.

Chukwuma, O.B., Rafatullah, M., Tajarudin, H.A., Ismail, N., 2020. Lignocellulolytic Enzymes in Biotechnological and Industrial Processes: A Review. Sustainability 12, https://doi.org/10.3390/su12187282.

Chung, D., Kwon, Y.M., Yang, Y., 2021. Telomere-to-telomere genome assembly of asparaginaseproducing Trichoderma simmonsii. BMC Genomics 22, 830. https://doi.org/10.1186/s12864021-08162-4.

Cingolani, P., Platts, A., Wang, L.L., Coon, M., Nguyen, T., Wang, L., Land, S.J., Lu, X., Ruden, D.M., 2012. A program for annotating and predicting the effects of single nucleotide polymorphisms, SnpEff: SNPs in the genome of Drosophila melanogaster strain w1118; iso2; iso-3. Fly 6, 80-92. https://doi.org/10.4161/fly.19695.

Corrêa, C.L., Midorikawa, G.E.O., Filho, E.X.F., Noronha, E.F., Alves, G.S.C., Togawa, R.C., SilvaJunior, O.B., Costa, M.M.d.C., Grynberg, P., Miller, R.N.G., 2020. Transcriptome ProfilingBased Analysis of Carbohydrate-Active Enzymes in Aspergillus terreus Involved in Plant Biomass Degradation. Frontiers in Bioengineering and Biotechnology 8, https://doi.org/10.3389/fbioe.2020.564527.

Courtine, D., Provaznik, J., Reboul, J., Blanc, G., Benes, V., Ewbank, J.J., 2020. Long-read only assembly of Drechmeria coniospora genomes reveals widespread chromosome plasticity and illustrates the limitations of current nanopore methods. GigaScience 9, https://doi.org/10.1093/gigascience/giaa099.

Couturier, M., Ladevèze, S., Sulzenbacher, G., Ciano, L., Fanuel, M., Moreau, C., Villares, A., Cathala, B., Chaspoul, F., Frandsen, K.E., Labourel, A., Herpoël-Gimbert, I., Grisel, S., Haon, M., Lenfant, N., Rogniaux, H., Ropartz, D., Davies, G.J., Rosso, M.-N., Walton, P.H., Henrissat, B., Berrin, J.-G., 2018. Lytic xylan oxidases from wood-decay fungi unlock biomass degradation. Nature Chemical Biology 14, 306-310. https://doi.org/10.1038/nchembio.2558.

Crucello, A., Sforça, D.A., Horta, M.A.C., dos Santos, C.A., Viana, A.J.C., Beloti, L.L., de Toledo, M.A.S., Vincentz, M., Kuroshu, R.M., de Souza, A.P., 2015. Analysis of Genomic Regions of Trichoderma harzianum IOC-3844 Related to Biomass Degradation. PLOS ONE 10, e0122122. https://doi.org/10.1371/journal.pone.0122122.

Dal Molin, A., Minio, A., Griggio, F., Delledonne, M., Infantino, A., Aragona, M., 2018. The genome assembly of the fungal pathogen Pyrenochaeta lycopersici from Single-Molecule Real-Time sequencing sheds new light on its biological complexity. PLOS ONE 13, e0200217. https://doi.org/10.1371/journal.pone.0200217. 
638

639

640

641

642

643

644

645

646

647

648

649

650

651

652

653

654

655

656

657

658

659

660

661

662

663

664

665

666

667

668

669

670

671

672

673

674

675

676

677

678

679

680

Dana, C.M., Dotson-Fagerstrom, A., Roche, C.M., Kal, S.M., Chokhawala, H.A., Blanch, H.W., Clark, D.S., 2014. The importance of pyroglutamate in cellulase Cel7A. Biotechnology and Bioengineering 111, 842-847. https://doi.org/https://doi.org/10.1002/bit.25178.

de Vries, R.P., Riley, R., Wiebenga, A., Aguilar-Osorio, G., Amillis, S., Uchima, C.A., Anderluh, G., Asadollahi, M., Askin, M., Barry, K., Battaglia, E., Bayram, Ö., Benocci, T., Braus-

Stromeyer, S.A., Caldana, C., Cánovas, D., Cerqueira, G.C., Chen, F., Chen, W., Choi, C., Clum, A., dos Santos, R.A.C., Damásio, A.R.d.L., Diallinas, G., Emri, T., Fekete, E., Flipphi, M., Freyberg, S., Gallo, A., Gournas, C., Habgood, R., Hainaut, M., Harispe, M.L., Henrissat, B., Hildén, K.S., Hope, R., Hossain, A., Karabika, E., Karaffa, L., Karányi, Z., Kraševec, N., Kuo, A., Kusch, H., LaButti, K., Lagendijk, E.L., Lapidus, A., Levasseur, A., Lindquist, E., Lipzen, A., Logrieco, A.F., MacCabe, A., Mäkelä, M.R., Malavazi, I., Melin, P., Meyer, V., Mielnichuk, N., Miskei, M., Molnár, Á.P., Mulé, G., Ngan, C.Y., Orejas, M., Orosz, E., Ouedraogo, J.P., Overkamp, K.M., Park, H.-S., Perrone, G., Piumi, F., Punt, P.J., Ram, A.F.J., Ramón, A., Rauscher, S., Record, E., Riaño-Pachón, D.M., Robert, V., Röhrig, J., Ruller, R., Salamov, A., Salih, N.S., Samson, R.A., Sándor, E., Sanguinetti, M., Schütze, T., Sepčić, K., Shelest, E., Sherlock, G., Sophianopoulou, V., Squina, F.M., Sun, H., Susca, A., Todd, R.B., Tsang, A., Unkles, S.E., van de Wiele, N., van Rossen-Uffink, D., Oliveira, J.V.d.C., Vesth, T.C., Visser, J., Yu, J.-H., Zhou, M., Andersen, M.R., Archer, D.B., Baker, S.E., Benoit, I., Brakhage, A.A., Braus, G.H., Fischer, R., Frisvad, J.C., Goldman, G.H., Houbraken, J., Oakley, B., Pócsi, I., Scazzocchio, C., Seiboth, B., vanKuyk, P.A., Wortman, J., Dyer, P.S., Grigoriev, I.V., 2017. Comparative genomics reveals high biological diversity and specific adaptations in the industrially and medically important fungal genus Aspergillus. Genome Biology 18, 28. https://doi.org/10.1186/s13059-017-1151-0.

Delabona, P.D.S., Codima, C.A., Ramoni, J., Zubieta, M.P., de Araujo, B.M., Farinas, C.S., Pradella, J., Seiboth, B., 2020a. The impact of putative methyltransferase overexpression on the Trichoderma harzianum cellulolytic system for biomass conversion. Bioresour Technol 313, 123616. https://doi.org/10.1016/j.biortech.2020.123616.

Delabona, P.D.S., Codima, C.A., Ramoni, J., Zubieta, M.P., de Araujo, B.M., Farinas, C.S., Pradella, J., Seiboth, B., 2020b. The impact of putative methyltransferase overexpression on the Trichoderma harzianum cellulolytic system for biomass conversion. Bioresour. Technol. 313, 123616. https://doi.org/10.1016/j.biortech.2020.123616.

Dodd, S.L., Lieckfeldt, E., Samuels, G.J., 2003. Hypocrea atroviridis sp. nov., the teleomorph of Trichoderma atroviride. Mycologia 95, 27-40. https://doi.org/10.1080/15572536.2004.11833129.

Druzhinina, I.S., Chenthamara, K., Zhang, J., Atanasova, L., Yang, D., Miao, Y., Rahimi, M.J., Grujic, M., Cai, F., Pourmehdi, S., Salim, K.A., Pretzer, C., Kopchinskiy, A.G., Henrissat, B., Kuo, A., Hundley, H., Wang, M., Aerts, A., Salamov, A., Lipzen, A., LaButti, K., Barry, K., Grigoriev, I.V., Shen, Q., Kubicek, C.P., 2018a. Massive lateral transfer of genes encoding plant cell wall-degrading enzymes to the mycoparasitic fungus Trichoderma from its plantassociated hosts. PLoS genetics 14, e1007322-e1007322. https://doi.org/10.1371/journal.pgen.1007322.

Druzhinina, I.S., Chenthamara, K., Zhang, J., Atanasova, L., Yang, D., Miao, Y., Rahimi, M.J., Grujic, M., Cai, F., Pourmehdi, S., Salim, K.A., Pretzer, C., Kopchinskiy, A.G., Henrissat, B., 
681

682

683

684

685

686

687

688

689

690

691

692

693

694

695

696

697

698

699

700

701

702

703

704

705

706

707

708

709

710

711

712

713

714

715

716

717

Kuo, A., Hundley, H., Wang, M., Aerts, A., Salamov, A., Lipzen, A., LaButti, K., Barry, K., Grigoriev, I.V., Shen, Q., Kubicek, C.P., 2018b. Massive lateral transfer of genes encoding plant cell wall-degrading enzymes to the mycoparasitic fungus Trichoderma from its plantassociated hosts. PLOS Genetics 14, e1007322. https://doi.org/10.1371/journal.pgen.1007322.

Druzhinina, I.S., Kopchinskiy, A.G., Kubicek, C.P., 2006. The first 100 Trichoderma species characterized by molecular data. Mycoscience 47, 55-64. https://doi.org/10.1007/s10267-0060279-7.

Druzhinina, I.S., Kubicek, C.P., Komoń-Zelazowska, M., Mulaw, T.B., Bissett, J., 2010. The Trichoderma harzianum demon: complex speciation history resulting in coexistence of hypothetical biological species, recent agamospecies and numerous relict lineages. BMC Evolutionary Biology 10, 94. https://doi.org/10.1186/1471-2148-10-94.

Emms, D.M., Kelly, S., 2015. OrthoFinder: solving fundamental biases in whole genome comparisons dramatically improves orthogroup inference accuracy. Genome Biology 16, 157. https://doi.org/10.1186/s13059-015-0721-2.

Emms, D.M., Kelly, S., 2017. STRIDE: Species Tree Root Inference from Gene Duplication Events. Molecular Biology and Evolution 34, 3267-3278. https://doi.org/10.1093/molbev/msx259.

Emms, D.M., Kelly, S., 2018. STAG: Species Tree Inference from All Genes. bioRxiv 267914. https://doi.org/10.1101/267914.

Emms, D.M., Kelly, S., 2019. OrthoFinder: phylogenetic orthology inference for comparative genomics. Genome Biology 20, 238. https://doi.org/10.1186/s13059-019-1832-y.

Fanelli, F., Liuzzi, V.C., Logrieco, A.F., Altomare, C., 2018. Genomic characterization of Trichoderma atrobrunneum (T. harzianum species complex) ITEM 908: insight into the genetic endowment of a multi-target biocontrol strain. BMC Genomics 19, 662. https://doi.org/10.1186/s12864-018-5049-3.

Fang, H., Li, C., Zhao, J., Zhao, C., 2021. Biotechnological Advances and Trends in Engineering Trichoderma reesei towards Cellulase Hyperproducer. Biotechnology and Bioprocess Engineering 26, 517-528. https://doi.org/10.1007/s12257-020-0243-y.

Ferreira Filho, J.A., Horta, M.A.C., Beloti, L.L., dos Santos, C.A., de Souza, A.P., 2017. Carbohydrate-active enzymes in Trichoderma harzianum: a bioinformatic analysis bioprospecting for key enzymes for the biofuels industry. BMC Genomics 18, 779. https://doi.org/10.1186/s12864-017-4181-9.

Finn, R.D., Clements, J., Eddy, S.R., 2011. HMMER web server: interactive sequence similarity searching. Nucleic acids research 39, W29-W37. https://doi.org/10.1093/nar/gkr367.

Fraceto, L.F., Maruyama, C.R., Guilger, M., Mishra, S., Keswani, C., Singh, H.B., de Lima, R., 2018. Trichoderma harzianum-based novel formulations: potential applications for management of Next-Gen agricultural challenges. Journal of Chemical Technology \& Biotechnology 93, 2056-2063. https://doi.org/https://doi.org/10.1002/jctb.5613. 
718

719

720

721

722

723

724

725

726

727

728

729

730

731

732

733

734

735

736

737

738

739

740

741

742

743

744

745

746

747

748

749

750

751

752

753

754

755

Gan, X., Cao, D., Zhang, Z., Cheng, S., Wei, L., Li, S., Liu, B., 2020. Draft Genome Assembly of Floccularia luteovirens, an Edible and Symbiotic Mushroom on Qinghai-Tibet Plateau. G3: Genes|Genomes|Genetics 10, 1167. https://doi.org/10.1534/g3.120.401037.

Ganesh Kumar, A., Manisha, D., Sujitha, K., Magesh Peter, D., Kirubagaran, R., Dharani, G., 2021. Genome sequence analysis of deep sea Aspergillus sydowii BOBA1 and effect of high pressure on biodegradation of spent engine oil. Scientific Reports 11, 9347. https://doi.org/10.1038/s41598-021-88525-9.

Guo, B., Sato, N., Biely, P., Amano, Y., Nozaki, K., 2016. Comparison of catalytic properties of multiple $\beta$-glucosidases of Trichoderma reesei. Applied Microbiology and Biotechnology 100, 4959-4968. https://doi.org/10.1007/s00253-016-7342-x.

Gurevich, A., Saveliev, V., Vyahhi, N., Tesler, G., 2013. QUAST: quality assessment tool for genome assemblies. Bioinformatics (Oxford, England) 29, 1072-1075. https://doi.org/10.1093/bioinformatics/btt086.

Hagestad, O.C., Hou, L., Andersen, J.H., Hansen, E.H., Altermark, B., Li, C., Kuhnert, E., Cox, R.J., Crous, P.W., Spatafora, J.W., Lail, K., Amirebrahimi, M., Lipzen, A., Pangilinan, J., Andreopoulos, W., Hayes, R.D., Ng, V., Grigoriev, I.V., Jackson, S.A., Sutton, T.D.S., Dobson, A.D.W., Rämä, T., 2021. Genomic characterization of three marine fungi, including Emericellopsis atlantica sp. nov. with signatures of a generalist lifestyle and marine biomass degradation. IMA Fungus 12, 21. https://doi.org/10.1186/s43008-021-00072-0.

Han, L., Tan, Y., Ma, W., Niu, K., Hou, S., Guo, W., Liu, Y., Fang, X., 2020. Precision Engineering of the Transcription Factor Cre1 in Hypocrea jecorina (Trichoderma reesei) for Efficient Cellulase Production in the Presence of Glucose. Frontiers in bioengineering and biotechnology 8, 852-852. https://doi.org/10.3389/fbioe.2020.00852.

Horta, M.A.C., Filho, J.A.F., Murad, N.F., de Oliveira Santos, E., dos Santos, C.A., Mendes, J.S., Brandão, M.M., Azzoni, S.F., de Souza, A.P., 2018. Network of proteins, enzymes and genes linked to biomass degradation shared by Trichoderma species. Scientific Reports 8, 1341. https://doi.org/10.1038/s41598-018-19671-w.

Horta, M.A.C., Thieme, N., Gao, Y., Burnum-Johnson, K.E., Nicora, C.D., Gritsenko, M.A., Lipton, M.S., Mohanraj, K., de Assis, L.J., Lin, L., Tian, C., Braus, G.H., Borkovich, K.A., Schmoll, M., Larrondo, L.F., Samal, A., Goldman, G.H., Benz, J.P., 2019. Broad Substrate-Specific Phosphorylation Events Are Associated With the Initial Stage of Plant Cell Wall Recognition in Neurospora crassa. Frontiers in Microbiology 10, https://doi.org/10.3389/fmicb.2019.02317.

Horta, M.A.C., Vicentini, R., Delabona, P.d.S., Laborda, P., Crucello, A., Freitas, S., Kuroshu, R.M., Polikarpov, I., Pradella, J.G.d.C., Souza, A.P., 2014. Transcriptome Profile of Trichoderma harzianum IOC-3844 Induced by Sugarcane Bagasse. PLOS ONE 9, e88689. https://doi.org/10.1371/journal.pone.0088689.

Institute, B., Picard Tools. Picard. Broad Institute, GitHub repository. 
756

757

758

759

760

761

762

763

764

765

766

767

768

769

770

771

772

773

774

775

776

777

778

779

780

781

782

783

784

785

786

787

788

789

790

791

792

793

794

795

796

797

798

Kappel, L., Münsterkötter, M., Sipos, G., Escobar Rodriguez, C., Gruber, S., 2020. Chitin and chitosan remodeling defines vegetative development and Trichoderma biocontrol. PLOS Pathogens 16, e1008320. https://doi.org/10.1371/journal.ppat.1008320.

Kidwai, M.K., Nehra, M., 2017. Biotechnological applications of Trichoderma species for environmental and food security, in: Gahlawat, S.K., Salar, R.K., Siwach, P., Duhan, J.S., Kumar, S., Kaur, P. (Eds.), Plant biotechnology: recent advancements and developments. Springer, Singapore, pp. 125-156.

Kjærbølling, I., Vesth, T., Frisvad, J.C., Nybo, J.L., Theobald, S., Kildgaard, S., Petersen, T.I., Kuo, A., Sato, A., Lyhne, E.K., Kogle, M.E., Wiebenga, A., Kun, R.S., Lubbers, R.J.M., Mäkelä, M.R., Barry, K., Chovatia, M., Clum, A., Daum, C., Haridas, S., He, G., LaButti, K., Lipzen, A., Mondo, S., Pangilinan, J., Riley, R., Salamov, A., Simmons, B.A., Magnuson, J.K., Henrissat, B., Mortensen, U.H., Larsen, T.O., de Vries, R.P., Grigoriev, I.V., Machida, M., Baker, S.E., Andersen, M.R., 2020. A comparative genomics study of 23 Aspergillus species from section Flavi. Nature Communications 11, 1106. https://doi.org/10.1038/s41467-01914051-y.

Koren, S., Walenz, B.P., Berlin, K., Miller, J.R., Bergman, N.H., Phillippy, A.M., 2017. Canu: scalable and accurate long-read assembly via adaptive k-mer weighting and repeat separation. Genome research 27, 722-736. https://doi.org/10.1101/gr.215087.116.

Krogh, A., Larsson, B., von Heijne, G., Sonnhammer, E.L.L., 2001. Predicting transmembrane protein topology with a hidden markov model: application to complete genomes11Edited by F. Cohen. Journal of Molecular Biology 305, 567-580. https://doi.org/https://doi.org/10.1006/jmbi.2000.4315.

Kubicek, C.P., Herrera-Estrella, A., Seidl-Seiboth, V., Martinez, D.A., Druzhinina, I.S., Thon, M., Zeilinger, S., Casas-Flores, S., Horwitz, B.A., Mukherjee, P.K., Mukherjee, M., Kredics, L., Alcaraz, L.D., Aerts, A., Antal, Z., Atanasova, L., Cervantes-Badillo, M.G., Challacombe, J., Chertkov, O., McCluskey, K., Coulpier, F., Deshpande, N., von Döhren, H., Ebbole, D.J., Esquivel-Naranjo, E.U., Fekete, E., Flipphi, M., Glaser, F., Gómez-Rodríguez, E.Y., Gruber, S., Han, C., Henrissat, B., Hermosa, R., Hernández-Oñate, M., Karaffa, L., Kosti, I., Le Crom, S., Lindquist, E., Lucas, S., Lübeck, M., Lübeck, P.S., Margeot, A., Metz, B., Misra, M., Nevalainen, H., Omann, M., Packer, N., Perrone, G., Uresti-Rivera, E.E., Salamov, A., Schmoll, M., Seiboth, B., Shapiro, H., Sukno, S., Tamayo-Ramos, J.A., Tisch, D., Wiest, A., Wilkinson, H.H., Zhang, M., Coutinho, P.M., Kenerley, C.M., Monte, E., Baker, S.E., Grigoriev, I.V., 2011. Comparative genome sequence analysis underscores mycoparasitism as the ancestral life style of Trichoderma. Genome Biology 12, R40. https://doi.org/10.1186/gb2011-12-4-r40.

Kubicek, C.P., Steindorff, A.S., Chenthamara, K., Manganiello, G., Henrissat, B., Zhang, J., Cai, F., Kopchinskiy, A.G., Kubicek, E.M., Kuo, A., Baroncelli, R., Sarrocco, S., Noronha, E.F., Vannacci, G., Shen, Q., Grigoriev, I.V., Druzhinina, I.S., 2019. Evolution and comparative genomics of the most common Trichoderma species. BMC Genomics 20, 485. https://doi.org/10.1186/s12864-019-5680-7.

Kurtz, S., Phillippy, A., Delcher, A.L., Smoot, M., Shumway, M., Antonescu, C., Salzberg, S.L., 2004. Versatile and open software for comparing large genomes. Genome Biology 5, R12. https://doi.org/10.1186/gb-2004-5-2-r12. 
799

800

801

802

803

804

805

806

807

808

809

810

811

812

813

814

815

816

817

818

819

820

821

822

823

824

825

826

827

828

829

830

831

832

833

834

835

836

837

838
Letunic, I., Bork, P., 2007. Interactive Tree Of Life (iTOL): an online tool for phylogenetic tree display and annotation. Bioinformatics 23, 127-128.

https://doi.org/10.1093/bioinformatics/btl529.

Levasseur, A., Drula, E., Lombard, V., Coutinho, P.M., Henrissat, B., 2013. Expansion of the enzymatic repertoire of the CAZy database to integrate auxiliary redox enzymes. Biotechnology for Biofuels 6, 41. https://doi.org/10.1186/1754-6834-6-41.

Li, B., Walton, J.D., 2017. Functional diversity for biomass deconstruction in family 5 subfamily 5 (GH5_5) of fungal endo- $\beta 1,4-$ glucanases. Applied Microbiology and Biotechnology 101, 4093-4101. https://doi.org/10.1007/s00253-017-8168-x.

Li, H., 2018. Minimap2: pairwise alignment for nucleotide sequences. Bioinformatics (Oxford, England) 34, 3094-3100. https://doi.org/10.1093/bioinformatics/bty191.

Li, H., Durbin, R., 2010. Fast and accurate long-read alignment with Burrows-Wheeler transform. Bioinformatics (Oxford, England) 26, 589-595. https://doi.org/10.1093/bioinformatics/btp698.

Li, W.-C., Huang, C.-H., Chen, C.-L., Chuang, Y.-C., Tung, S.-Y., Wang, T.-F., 2017. Trichoderma reesei complete genome sequence, repeat-induced point mutation, and partitioning of CAZyme gene clusters. Biotechnology for Biofuels 10, 170. https://doi.org/10.1186/s13068017-0825-X.

Mahmoud, M., Gobet, N., Cruz-Dávalos, D.I., Mounier, N., Dessimoz, C., Sedlazeck, F.J., 2019. Structural variant calling: the long and the short of it. Genome Biology 20, 246. https://doi.org/10.1186/s13059-019-1828-7.

Marçais, G., Delcher, A.L., Phillippy, A.M., Coston, R., Salzberg, S.L., Zimin, A., 2018. MUMmer4: A fast and versatile genome alignment system. PLOS Computational Biology 14, e1005944. https://doi.org/10.1371/journal.pcbi.1005944.

Martinez, D., Berka, R.M., Henrissat, B., Saloheimo, M., Arvas, M., Baker, S.E., Chapman, J., Chertkov, O., Coutinho, P.M., Cullen, D., Danchin, E.G.J., Grigoriev, I.V., Harris, P., Jackson, M., Kubicek, C.P., Han, C.S., Ho, I., Larrondo, L.F., de Leon, A.L., Magnuson, J.K., Merino, S., Misra, M., Nelson, B., Putnam, N., Robbertse, B., Salamov, A.A., Schmoll, M., Terry, A., Thayer, N., Westerholm-Parvinen, A., Schoch, C.L., Yao, J., Barabote, R., Nelson, M.A., Detter, C., Bruce, D., Kuske, C.R., Xie, G., Richardson, P., Rokhsar, D.S., Lucas, S.M., Rubin, E.M., Dunn-Coleman, N., Ward, M., Brettin, T.S., 2008. Genome sequencing and analysis of the biomass-degrading fungus Trichoderma reesei (syn. Hypocrea jecorina). Nature Biotechnology 26, 553-560. https://doi.org/10.1038/nbt1403.

Medeiros, H.A., Filho, J.V.A., Freitas, L.G., Castillo, P., Rubio, M.B., Hermosa, R., Monte, E., 2017. Tomato progeny inherit resistance to the nematode Meloidogyne javanica linked to plant growth induced by the biocontrol fungus Trichoderma atroviride. Sci Rep 7, 40216. https://doi.org/10.1038/srep40216.

Mills, R.E., Walter, K., Stewart, C., Handsaker, R.E., Chen, K., Alkan, C., Abyzov, A., Yoon, S.C., Ye, K., Cheetham, R.K., Chinwalla, A., Conrad, D.F., Fu, Y., Grubert, F., Hajirasouliha, I., Hormozdiari, F., Iakoucheva, L.M., Iqbal, Z., Kang, S., Kidd, J.M., Konkel, M.K., Korn, J., 
Khurana, E., Kural, D., Lam, H.Y.K., Leng, J., Li, R., Li, Y., Lin, C.-Y., Luo, R., Mu, X.J., Nemesh, J., Peckham, H.E., Rausch, T., Scally, A., Shi, X., Stromberg, M.P., Stütz, A.M., Urban, A.E., Walker, J.A., Wu, J., Zhang, Y., Zhang, Z.D., Batzer, M.A., Ding, L., Marth, G.T., McVean, G., Sebat, J., Snyder, M., Wang, J., Ye, K., Eichler, E.E., Gerstein, M.B., Hurles, M.E., Lee, C., McCarroll, S.A., Korbel, J.O., Genomes, P., 2011. Mapping copy number variation by population-scale genome sequencing. Nature 470, 59-65. https://doi.org/10.1038/nature09708.

Mitsuhashi, S., Matsumoto, N., 2020. Long-read sequencing for rare human genetic diseases. Journal of Human Genetics 65, 11-19. https://doi.org/10.1038/s10038-019-0671-8.

Miyauchi, S., Kiss, E., Kuo, A., Drula, E., Kohler, A., Sánchez-García, M., Morin, E., Andreopoulos, B., Barry, K.W., Bonito, G., Buée, M., Carver, A., Chen, C., Cichocki, N., Clum, A., Culley, D., Crous, P.W., Fauchery, L., Girlanda, M., Hayes, R.D., Kéri, Z., LaButti, K., Lipzen, A., Lombard, V., Magnuson, J., Maillard, F., Murat, C., Nolan, M., Ohm, R.A., Pangilinan, J., Pereira, M.d.F., Perotto, S., Peter, M., Pfister, S., Riley, R., Sitrit, Y., Stielow, J.B., Szöllősi, G., Žifčáková, L., Štursová, M., Spatafora, J.W., Tedersoo, L., Vaario, L.-M., Yamada, A., Yan, M., Wang, P., Xu, J., Bruns, T., Baldrian, P., Vilgalys, R., Dunand, C., Henrissat, B., Grigoriev, I.V., Hibbett, D., Nagy, L.G., Martin, F.M., 2020. Large-scale genome sequencing of mycorrhizal fungi provides insights into the early evolution of symbiotic traits. Nature Communications 11, 5125. https://doi.org/10.1038/s41467-020-18795-w.

Monclaro, A.V., Filho, E.X.F., 2017. Fungal lytic polysaccharide monooxygenases from family AA9: Recent developments and application in lignocelullose breakdown. International Journal of Biological Macromolecules 102, 771-778. https://doi.org/https://doi.org/10.1016/j.ijbiomac.2017.04.077.

Montoliu-Nerin, M., Sánchez-García, M., Bergin, C., Grabherr, M., Ellis, B., Kutschera, V.E., Kierczak, M., Johannesson, H., Rosling, A., 2020. Building de novo reference genome assemblies of complex eukaryotic microorganisms from single nuclei. Scientific Reports 10, 1303. https://doi.org/10.1038/s41598-020-58025-3.

Motta, M.L.L., Filho, J.A.F., de Melo, R.R., Zanphorlin, L.M., dos Santos, C.A., de Souza, A.P., 2021. A novel fungal metal-dependent $\alpha$-l-arabinofuranosidase of family 54 glycoside hydrolase shows expanded substrate specificity. Scientific Reports 11, 10961. https://doi.org/10.1038/s41598-021-90490-2.

Nagel, J.H., Wingfield, M.J., Slippers, B., 2021. Increased abundance of secreted hydrolytic enzymes and secondary metabolite gene clusters define the genomes of latent plant pathogens in the Botryosphaeriaceae. BMC Genomics 22, 589. https://doi.org/10.1186/s12864-021-07902-w.

Najjarzadeh, N., Matsakas, L., Rova, U., Christakopoulos, P., 2021. How Carbon Source and Degree of Oligosaccharide Polymerization Affect Production of Cellulase-Degrading Enzymes by Fusarium oxysporum f. sp. lycopersici. Frontiers in Microbiology 12, https://doi.org/10.3389/fmicb.2021.652655.

Nakkeeran, S., Marimuthu, T., Renukadevi, P., Brindhadevi, S., Jogaiah, S., 2021. 24 - Exploring the biogeographical diversity of Trichoderma for plant health, in: Jogaiah, S. (Ed.), Biocontrol Agents and Secondary Metabolites. Woodhead Publishing, pp. 537-571. 
880

881

882

883

884

885

886

887

888

889

890

891

892

893

894

895

896

897

898

899

900

901

902

903

904

905

906

907

908

909

910

911

912

913

914

915

916

917

918

Okonechnikov, K., Conesa, A., García-Alcalde, F., 2016. Qualimap 2: advanced multi-sample quality control for high-throughput sequencing data. Bioinformatics (Oxford, England) 32, 292-294. https://doi.org/10.1093/bioinformatics/btv566.

Priest, S.J., Yadav, V., Heitman, J., 2020. Advances in understanding the evolution of fungal genome architecture. F1000Research 9, F1000 Faculty Rev-1776. https://doi.org/10.12688/f1000research.25424.1.

Ramazi, S., Zahiri, J., 2021. Post-translational modifications in proteins: resources, tools and prediction methods. Database 2021, baab012. https://doi.org/10.1093/database/baab012.

Rosolen, R.R., Aono, A.H., Almeida, D.A., Filho, J.A.F., Horta, M.A.C., de Souza, A.P., 2021. Network analysis reveals different strategies of Trichoderma spp. associated with XYR1 and CRE1 during cellulose degradation. bioRxiv 2020.2005.2002.074344. https://doi.org/10.1101/2020.05.02.074344.

Sakamoto, Y., Sereewattanawoot, S., Suzuki, A., 2020. A new era of long-read sequencing for cancer genomics. Journal of Human Genetics 65, 3-10. https://doi.org/10.1038/s10038-019-0658-5.

Saravanakumar, K., Li, Y., Yu, C., Wang, Q.Q., Wang, M., Sun, J., Gao, J.X., Chen, J., 2017. Effect of Trichoderma harzianum on maize rhizosphere microbiome and biocontrol of Fusarium Stalk rot. Sci Rep 7, 1771. https://doi.org/10.1038/s41598-017-01680-w.

Schmoll, M., 2018. Regulation of plant cell wall degradation by light in Trichoderma. Fungal Biology and Biotechnology 5, 10. https://doi.org/10.1186/s40694-018-0052-7.

Schmoll, M., Dattenböck, C., Carreras-Villaseñor, N., Mendoza-Mendoza, A., Tisch, D., Alemán, M.I., Baker, S.E., Brown, C., Cervantes-Badillo, M.G., Cetz-Chel, J., Cristobal-Mondragon, G.R., Delaye, L., Esquivel-Naranjo, E.U., Frischmann, A., Gallardo-Negrete, J.d.J., GarcíaEsquivel, M., Gomez-Rodriguez, E.Y., Greenwood, D.R., Hernández-Oñate, M., Kruszewska, J.S., Lawry, R., Mora-Montes, H.M., Muñoz-Centeno, T., Nieto-Jacobo, M.F., Nogueira Lopez, G., Olmedo-Monfil, V., Osorio-Concepcion, M., Piłsyk, S., Pomraning, K.R., Rodriguez-Iglesias, A., Rosales-Saavedra, M.T., Sánchez-Arreguín, J.A., Seidl-Seiboth, V., Stewart, A., Uresti-Rivera, E.E., Wang, C.-L., Wang, T.-F., Zeilinger, S., Casas-Flores, S., Herrera-Estrella, A., 2016. The Genomes of Three Uneven Siblings: Footprints of the Lifestyles of Three Trichoderma Species. Microbiology and molecular biology reviews : MMBR 80, 205-327. https://doi.org/10.1128/MMBR.00040-15.

Sedlazeck, F.J., Rescheneder, P., Smolka, M., Fang, H., Nattestad, M., von Haeseler, A., Schatz, M.C., 2018. Accurate detection of complex structural variations using single-molecule sequencing. Nature methods 15, 461-468. https://doi.org/10.1038/s41592-018-0001-7.

Sharma, S., Kour, D., Rana, K.L., Dhiman, A., Thakur, S., Thakur, P., Thakur, S., Thakur, N., Sudheer, S., Yadav, N., Yadav, A.N., Rastegari, A.A., Singh, K., 2019. Trichoderma: Biodiversity, Ecological Significances, and Industrial Applications, in: Yadav, A.N., Mishra, S., Singh, S., Gupta, A. (Eds.), Recent Advancement in White Biotechnology Through Fungi: Volume 1: Diversity and Enzymes Perspectives. Springer International Publishing, Cham, pp. 85-120. 
919

920

921

922

923

924

925

926

927

928

929

930

931

932

933

934

935

936

937

938

939

940

941

942

943

944

945

946

947

948

949

950

951

952

953

954

955

956

957

958

Simão, F.A., Waterhouse, R.M., Ioannidis, P., Kriventseva, E.V., Zdobnov, E.M., 2015. BUSCO: assessing genome assembly and annotation completeness with single-copy orthologs. Bioinformatics 31, 3210-3212. https://doi.org/10.1093/bioinformatics/btv351.

Stanke, M., Keller, O., Gunduz, I., Hayes, A., Waack, S., Morgenstern, B., 2006. AUGUSTUS: ab initio prediction of alternative transcripts. Nucleic Acids Research 34, W435-W439. https://doi.org/10.1093/nar/gk1200.

Tatusov, R.L., Galperin, M.Y., Natale, D.A., Koonin, E.V., 2000. The COG database: a tool for genome-scale analysis of protein functions and evolution. Nucleic acids research 28, 33-36. https://doi.org/10.1093/nar/28.1.33.

Thanh, V.N., Thuy, N.T., Huong, H.T.T., Hien, D.D., Hang, D.T.M., Anh, D.T.K., Hüttner, S., Larsbrink, J., Olsson, L., 2019. Surveying of acid-tolerant thermophilic lignocellulolytic fungi in Vietnam reveals surprisingly high genetic diversity. Scientific reports 9, 3674-3674. https://doi.org/10.1038/s41598-019-40213-5.

The UniProt, C., 2021. UniProt: the universal protein knowledgebase in 2021. Nucleic Acids Research 49, D480-D489. https://doi.org/10.1093/nar/gkaa1100.

Törönen, P., Medlar, A., Holm, L., 2018. PANNZER2: a rapid functional annotation web server. Nucleic acids research 46, W84-W88. https://doi.org/10.1093/nar/gky350.

van Eerde, A., Várnai, A., Jameson, J.K., Paruch, L., Moen, A., Anonsen, J.H., Chylenski, P., Steen, H.S., Heldal, I., Bock, R., Eijsink, V.G.H., Liu-Clarke, J., 2020. In-depth characterization of Trichoderma reesei cellobiohydrolase TrCel7A produced in Nicotiana benthamiana reveals limitations of cellulase production in plants by host-specific post-translational modifications. Plant biotechnology journal 18, 631-643. https://doi.org/10.1111/pbi.13227.

Varga, T., Krizsán, K., Földi, C., Dima, B., Sánchez-García, M., Sánchez-Ramírez, S., Szöllősi, G.J., Szarkándi, J.G., Papp, V., Albert, L., Andreopoulos, W., Angelini, C., Antonín, V., Barry, K.W., Bougher, N.L., Buchanan, P., Buyck, B., Bense, V., Catcheside, P., Chovatia, M., Cooper, J., Dämon, W., Desjardin, D., Finy, P., Geml, J., Haridas, S., Hughes, K., Justo, A., Karasiński, D., Kautmanova, I., Kiss, B., Kocsubé, S., Kotiranta, H., LaButti, K.M., Lechner, B.E., Liimatainen, K., Lipzen, A., Lukács, Z., Mihaltcheva, S., Morgado, L.N., Niskanen, T., Noordeloos, M.E., Ohm, R.A., Ortiz-Santana, B., Ovrebo, C., Rácz, N., Riley, R., Savchenko, A., Shiryaev, A., Soop, K., Spirin, V., Szebenyi, C., Tomšovský, M., Tulloss, R.E., Uehling, J., Grigoriev, I.V., Vágvölgyi, C., Papp, T., Martin, F.M., Miettinen, O., Hibbett, D.S., Nagy, L.G., 2019. Megaphylogeny resolves global patterns of mushroom evolution. Nature ecology \& evolution 3, 668-678. https://doi.org/10.1038/s41559-019-0834-1.

Wei, H., Wu, M., Fan, A., Su, H., 2021. Recombinant protein production in the filamentous fungus Trichoderma. Chinese Journal of Chemical Engineering 30, 74-81. https://doi.org/https://doi.org/10.1016/j.cjche.2020.11.006.

Wu, J.Q., Dong, C., Song, L., Park, R.F., 2020. Long-Read-Based de novo Genome Assembly and Comparative Genomics of the Wheat Leaf Rust Pathogen Puccinia triticina Identifies Candidates for Three Avirulence Genes. Frontiers in Genetics 11, https://doi.org/10.3389/fgene.2020.00521. 
959

960

961

962

963

964

965

966

967

968

969

970

971

972

973

974

975

976

977

978

979

980

981

982

983

984

985

986

987

988

989

990

991

992

993

994

995

996

997

998

999
Wu, L., McCluskey, K., Desmeth, P., Liu, S., Hideaki, S., Yin, Y., Moriya, O., Itoh, T., Kim, C.Y., Lee, J.-S., Zhou, Y., Kawasaki, H., Hazbón, M.H., Robert, V., Boekhout, T., Lima, N., Evtushenko, L., Boundy-Mills, K., Bunk, B., Moore, E.R.B., Eurwilaichitr, L., Ingsriswang, S., Shah, H., Yao, S., Jin, T., Huang, J., Shi, W., Sun, Q., Fan, G., Li, W., Li, X., Kurtböke, İ., $\mathrm{Ma}, \mathrm{J} ., 2018$. The global catalogue of microorganisms 10K type strain sequencing project: closing the genomic gaps for the validly published prokaryotic and fungi species. GigaScience 7, https://doi.org/10.1093/gigascience/giy026.

Xie, B.-B., Qin, Q.-L., Shi, M., Chen, L.-L., Shu, Y.-L., Luo, Y., Wang, X.-W., Rong, J.-C., Gong, Z.-T., Li, D., Sun, C.-Y., Liu, G.-M., Dong, X.-W., Pang, X.-H., Huang, F., Liu, W., Chen, X.-L., Zhou, B.-C., Zhang, Y.-Z., Song, X.-Y., 2014. Comparative Genomics Provide Insights into Evolution of Trichoderma Nutrition Style. Genome Biology and Evolution 6, 379-390. https://doi.org/10.1093/gbe/evu018.

Zhang, H., Yohe, T., Huang, L., Entwistle, S., Wu, P., Yang, Z., Busk, P.K., Xu, Y., Yin, Y., 2018. dbCAN2: a meta server for automated carbohydrate-active enzyme annotation. Nucleic Acids Research 46, W95-W101. https://doi.org/10.1093/nar/gky418.

Zhang, Y., Yang, J., Luo, L., Wang, E., Wang, R., Liu, L., Liu, J., Yuan, H., 2020a. Low-cost cellulase-hemicellulase mixture secreted by Trichoderma harzianum EM0925 with complete saccharification efficacy of lignocellulose. Int J Mol Sci 21, 371. https://doi.org/10.3390/ijms21020371.

Zhang, Y., Yang, J., Luo, L., Wang, E., Wang, R., Liu, L., Liu, J., Yuan, H., 2020b. Low-cost cellulase-hemicellulase mixture secreted by Trichoderma harzianum EM0925 with complete saccharification efficacy of lignocellulose. Int. J. Mol. Sci. 21, 371. https://doi.org/10.3390/ijms21020371.

Zin, N.A., Badaluddin, N.A., 2020. Biological functions of Trichoderma spp. for agriculture applications. Annals of Agricultural Sciences 65, 168-178. https://doi.org/https://doi.org/10.1016/j.aoas.2020.09.003. 
$1000 \quad$ Figure legends

1001 Figure 1. Trichoderma isolates evaluated in this study. (A) Th3844, (B) Th0179, (C) Tr0711, and

1002 (D) Ta0020 cultivated on potato dextrose broth (PDA) solid medium at $28{ }^{\circ} \mathrm{C}$. After DNA extraction, 1003 their genome was sequenced and assembled. Ta0020: T. atroviride CBMAI-0020; Th0179: T.

1004 harzianum CBMAI-0179; Th3844: T. harzianum IOC-3844; Tr0711: T. reesei CBMAI-0711.

1005 Figure 2. Comparisons between the genomes of the analyzed Trichoderma isolates and the $\boldsymbol{T}$. 1006 reesei QM6a reference genome. Dot plots of the assemblies of (A) Th3844, (B) Th0179, (C) $\mathrm{Ta} 0020$, and (D) Tr0711 that were generated by Canu (y-axis) against those from T. reesei QM6a ( $\mathrm{x}$ axis) that are available in the NCBI database. Ta0020: T. atroviride CBMAI-0020; Th0179: T. harzianum CBMAI-0179; Th3844: T. harzianum IOC-3844; Tr0711: T. reesei CBMAI-0711.

Figure 3. COG functional category distribution of the Trichoderma isolates considered. The plot shows the number of genes in the genomes of (A) Th3844, (B) Th0179, (C) Ta0020, and (D) Tr0711, in which a COG classification was obtained. The size of the boxes represents the abundance of the genes at the level of individual COG families. Only the COG functional categories with more than a hundred counts were represented. Ta0020: T. atroviride CBMAI-0020; Th0179: T. harzianum CBMAI-0179; Th3844: T. harzianum IOC-3844; Tr0711: T. reesei CBMAI-0711.

Figure 4. Distribution of CAZymes in Trichoderma spp. (A) The predicted CAZymes from the assembled genomes were classified according to the CAZy database. (B) The secreted CAZymes were grouped according to their CAZyme class. CAZymes: carbohydrate-active enzymes; Ta0020: $T$. atroviride CBMAI-0020; Th0179: T. harzianum CBMAI-0179; Th3844: T. harzianum IOC-3844; Tr0711: T. reesei CBMAI-0711. AA: auxiliary activity; CBM: carbohydrate-binding module; EC: carbohydrate esterase; GH: glycosyl hydrolase; GT: glycosyl transferase; PL: polysaccharide lyase.

1022 Figure 5. Quantitative comparison of the biomass-degrading enzyme repertoires of

1023 Trichoderma isolates. Heatmap of the number of enzymes in each CAZY family from the Th3844, Th0179, Ta0020, and Tr0711 genomes. This map includes only the enzymes/proteins related to biomass degradation. Ta0020: T. atroviride CBMAI-0020; Th0179: T. harzianum CBMAI-0179; Th3844: T. harzianum IOC-3844; Tr0711: T. reesei CBMAI-0711; LPMOs: Lytic polysaccharide monooxygenases; CDHs: Cellobiose dehydrogenases; PHDs: Pyranose dehydrogenases.

1028 Figure 6. Phylogenetic relationships of Trichoderma spp. as inferred by an orthology analysis. The phylogenetic tree modeled by OrthoFinder software was based on the concatenation of 2,229 single copy orthogroups. In addition to the proteomes of Th3844, Th0179, Ta0020, and Tr0711, this methodology shows the inferred relationships among 19 Trichoderma spp., for which the proteomes are available in the NCBI database. Fusarium spp., Aspergillus spp., and Neurospora spp. were used as the outgroup. Bootstrap values are shown at the nodes.

1034 Figure 7. Structural variant heterogeneity across the genomes of the evaluated Trichoderma spp. (A) Long-read alignment-based structural variant (SV) analyses among the evaluated Trichoderma isolates and T. reesei QM6a showed breakends (BNDs), deletions (DELs), multiple nucleotides and InDels (MIXEDs), duplications (DUPs), insertions (INSs), and inversions (INVs) between the genomes. (B) Functional effects of the identified SVs. Ta0020: T. atroviride CBMAI- 
1042 Tables

1043 Table 1. Genome assembly and annotation statistics.

\begin{tabular}{|lllll}
\hline & Th3844 & Th0179 & Ta0020 & Tr0711 \\
\hline Number of reads & 418,031 & 504,913 & 458,142 & 282,252 \\
\hline Genome size (bp) & $40,219,724$ & $39,170,259$ & $36,411,897$ & $32,448,670$ \\
\hline GC content (\%) & 47.5 & 49.4 & 49.5 & 53.5 \\
\hline N50 reads & $3,607,994$ & $2,983,622$ & $3,146,023$ & $1,694,659$ \\
\hline L50 contigs & 5 & 6 & 5 & 7 \\
\hline Number of contigs & 15 & 18 & 14 & 26 \\
\hline Complete BUSCOs (\%) & 90.1 & 98.7 & 99 & 99.1 \\
\hline Complete and single-copy BUSCOs (\%) & 89.6 & 98.1 & 98.8 & 98.9 \\
\hline Complete and duplicated BUSCOs (\%) & 0.5 & 0.6 & 0.2 & 0.2 \\
\hline Fragmented BUSCOs (\%) & 0.2 & 0.2 & 0.1 & 0.1 \\
\hline Missing (\%) & 9.7 & 1.1 & 0.9 & 0.8 \\
\hline Number of predicted genes & 10,786 & 11,322 & 10,082 & 8,796 \\
\hline Number of annotated genes & 10,611 & 11,065 & 9,547 & 8,495 \\
\hline
\end{tabular}

1044

1045

1046

1047

1048

1049

1050

1051

1052

1053

1054

1055

1056

1057

1058

1059

1060

1061

1062

1063

1064

1065

1066

1067 
1068 Table 2. Comparison of the genome features of Trichoderma spp. genomes.

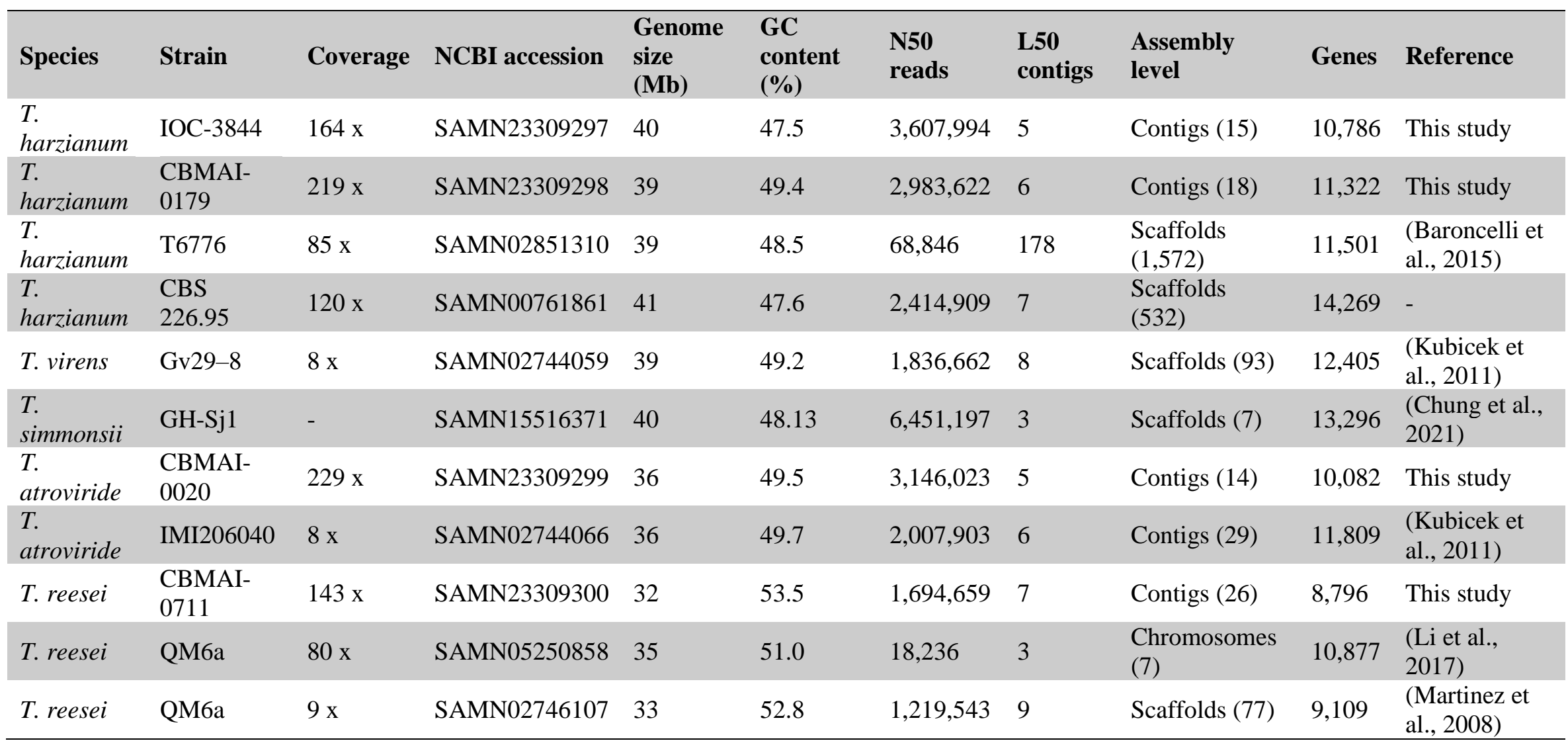

1069 
bioRxiv preprint doi: https://doi.org/10.1101/2022.02 11.479986; this version posted February 11,2022 . The copyright holder for this preprint (which was not certified by peer review) is the author/funder, who has granted bioRxiv a license to display the preprint in perpetuity. It is made available under aCC-BY-NC-ND 4.0 International license.

1074 Table 3. Distribution of Th3844, Th0179, Ta0020, and Tr0711 orthologs.

\begin{tabular}{lllll}
\hline & Th3844 & Th0179 & Ta0020 & Tr0711 \\
Th3844 & - & 9,729 & 7,927 & 7,330 \\
Th0179 & 9,729 & - & 8,755 & 8,141 \\
Ta0020 & 7,927 & 8,755 & - & 7,784 \\
Tr0711 & 7,330 & 8,141 & 7,784 & - \\
\hline
\end{tabular}


$\mathbf{A}$

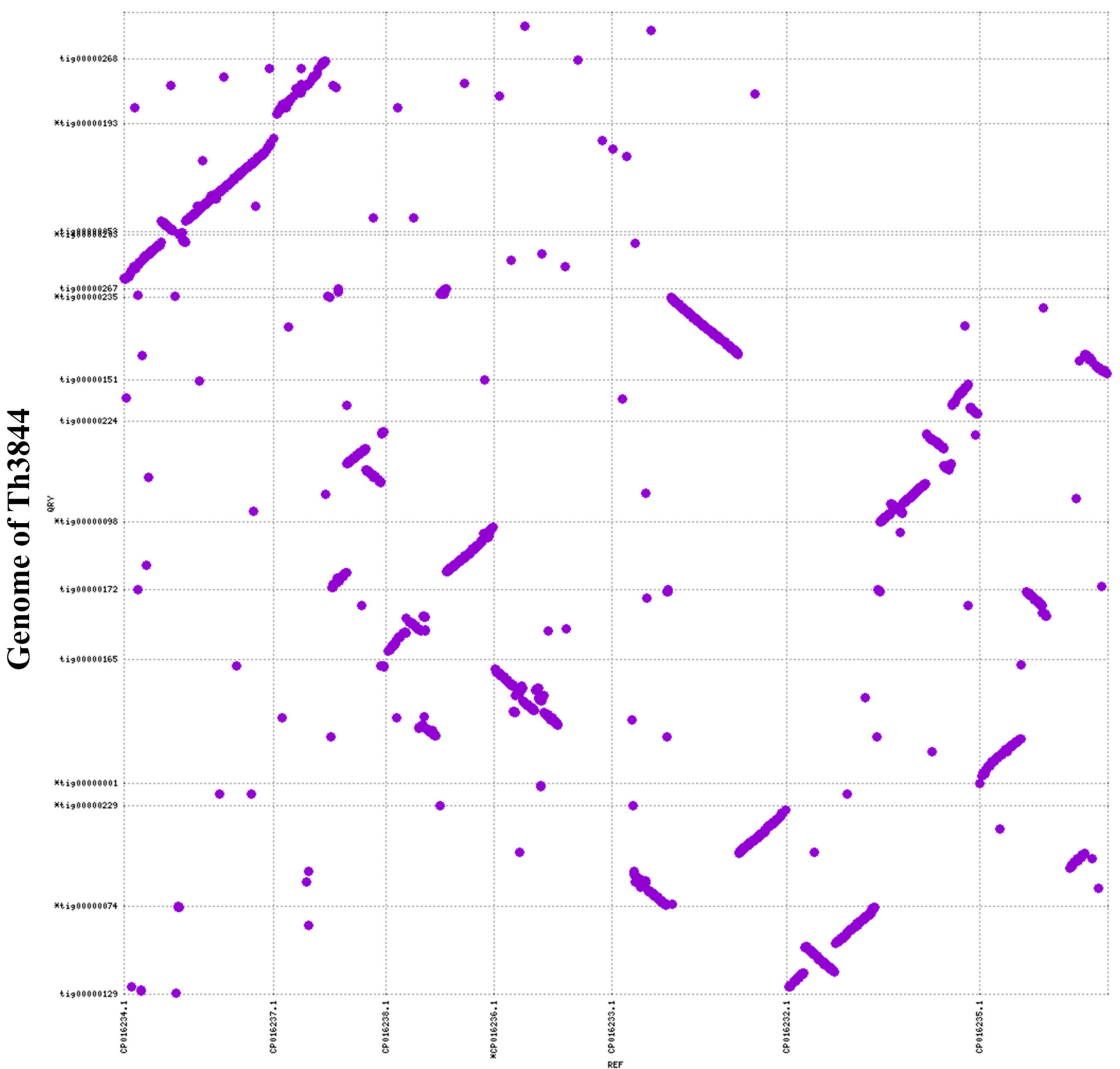

B

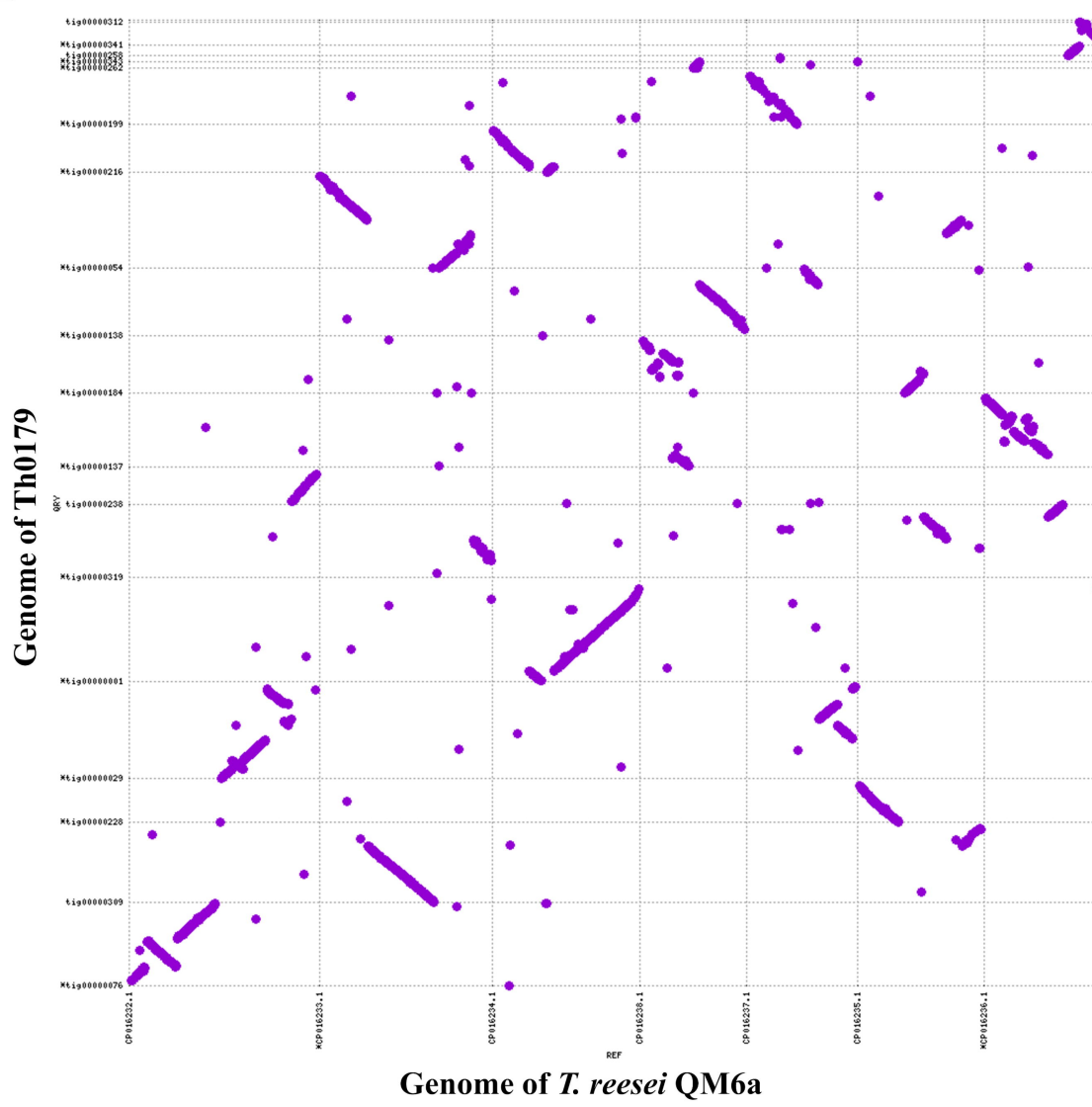

$\mathrm{C}$
C

Genome of T. reesei QM6a

D
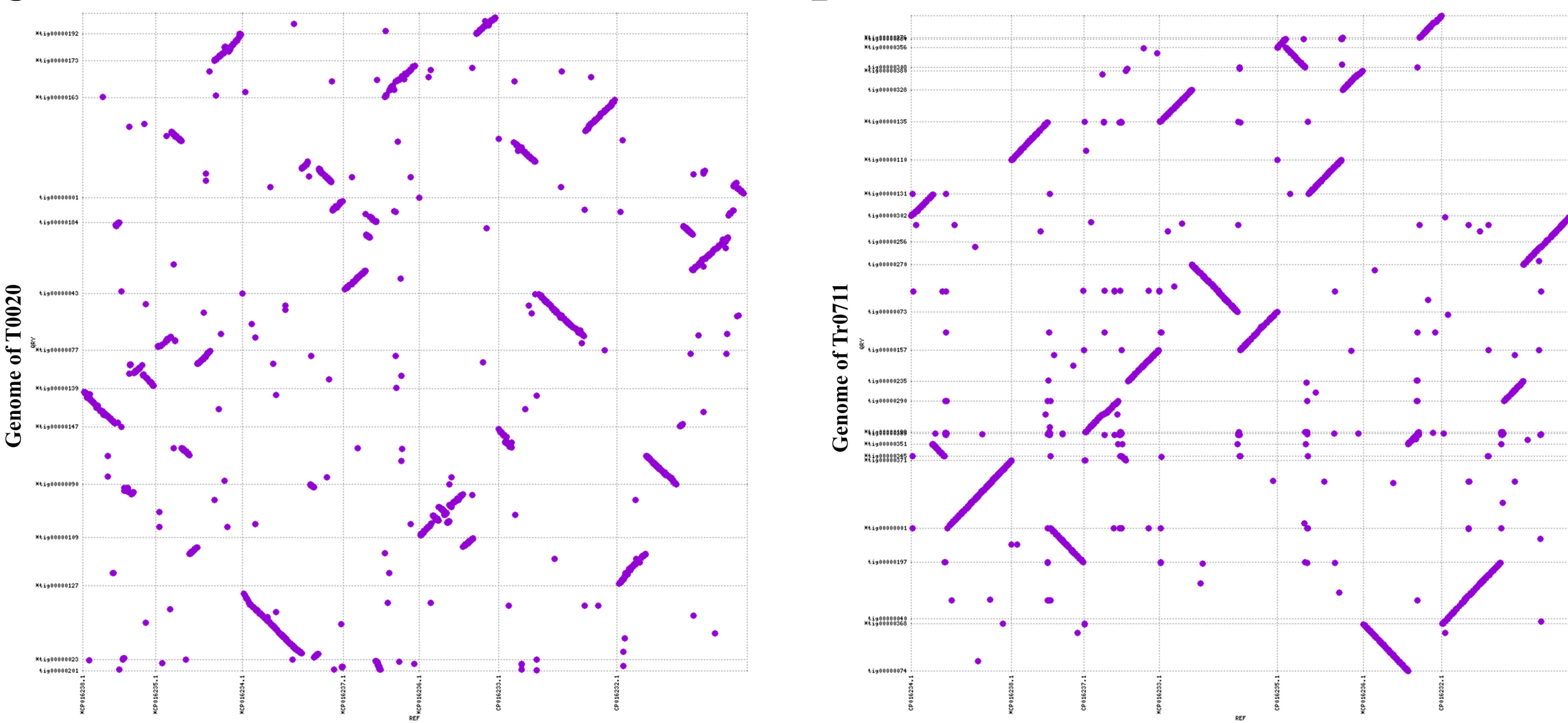

Genome of $T$. reesei QM6a

Genome of $T$. reesei QM6a 
Arabinan

Cellulose

Esterases

Lignin

Pectin

Soluble oligosaccharides

Xylan

Xylosidases//-glucosidases
Arabinofuranosidases

Endoarabinanases

Cellobiohydrolases

Oligosaccharide oxidases

$$
\text { LPMOs }
$$

Endoglucanases

Feruloyl/p-coumaroyl/acetyl esterases 4-O-methyl-glucoronoyl esterases

Acetyl esterases

Glyoxal oxidases (GLOX)

1,4-benzoquinone reductases

Vanillyl-alcohol oxidases

Peroxidases

Laccases

Oxidoreductases/CDHs

PDHs

Pectin lyases

Pectin methylesterases

Rhamnosidases

Pectin lyases

Polygalacturonases

$\beta$-glucosidases

Mannosidases

Xylanases

LPMOs

Xylanases

Xylosidases $/ \beta$-glucosidases
GH51

GH54

GH43

GH6

AA7

AA9

GH5

CE1

CE15

CE5

AA5

AA6

AA4

AA2

AA1

AA3

AA12

PL1

CE8

GH78

PL20

GH28

GH1

$\mathrm{GH} 2$

GH10

AA14

GH11

GH3

\begin{tabular}{ccccc}
\hline $\mathbf{0}$ & $\mathbf{0}$ & $\mathbf{1}$ & $\mathbf{0}$ \\
2 & 2 & 2 & 2 \\
5 & 4 & 4 & 2 \\
1 & 1 & 1 & 1 \\
2 & 3 & 1 & 1 \\
3 & 3 & 3 & 3 \\
10 & 10 & 9 & 7 \\
1 & $\mathbf{0}$ & $\mathbf{0}$ & $\mathbf{0}$ \\
1 & 1 & 1 & 1 \\
4 & 4 & 3 & 4 \\
1 & 1 & 1 & 1 \\
1 & 1 & 1 & 1 \\
2 & 3 & 0 & 0 \\
1 & 3 & 5 & 3 \\
9 & 9 & 6 & 4 \\
19 & 20 & 12 & 12 \\
\hline 1 & 1 & 1 & 0 \\
\hline 0 & 0 & 1 & 0 \\
1 & 1 & 1 & 0 \\
2 & 2 & 2 & 1 \\
2 & 2 & 2 & 2 \\
5 & 5 & 5 & 4 \\
4 & 4 & 4 & 2 \\
11 & 13 & 10 & 7 \\
\hline 2 & 2 & 1 & 1 \\
4 & 2 & 2 & 2 \\
16 & 17 & 15 & 12 \\
\hline
\end{tabular}




\section{bootstrap}

- 0.062

0.3

0.53

0.76 1 
Tr0711 -

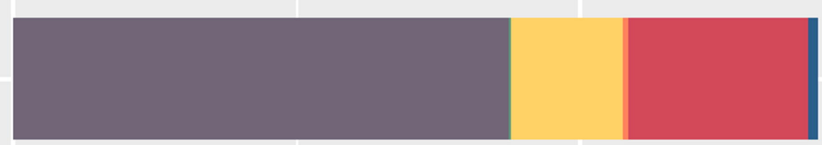

BND

DEL

Th3844 -

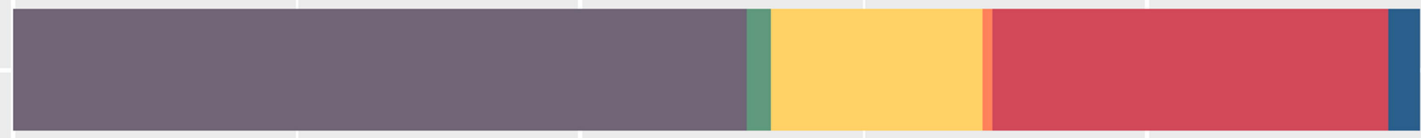

Th0179-

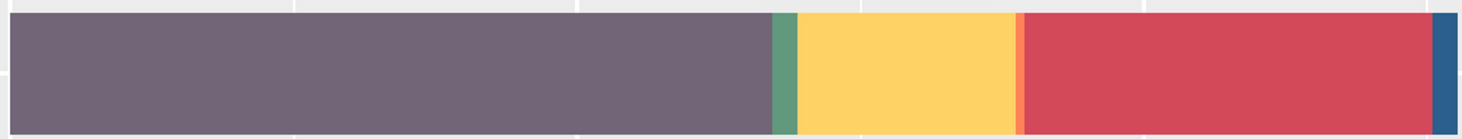

Ta0020 -
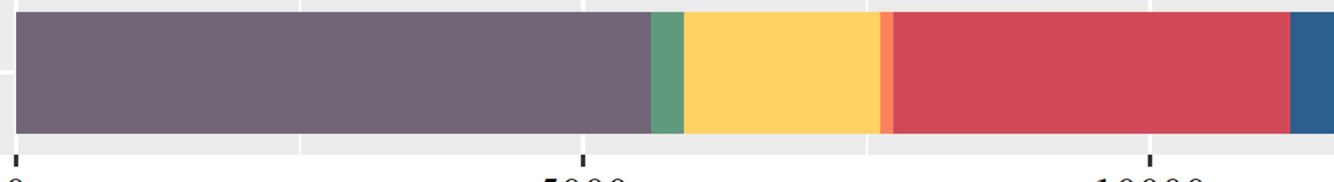

5000

10000

Number of variants

B

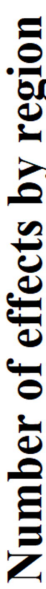
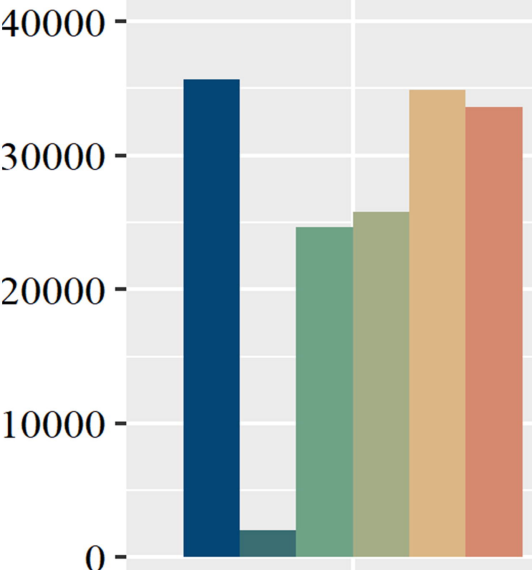

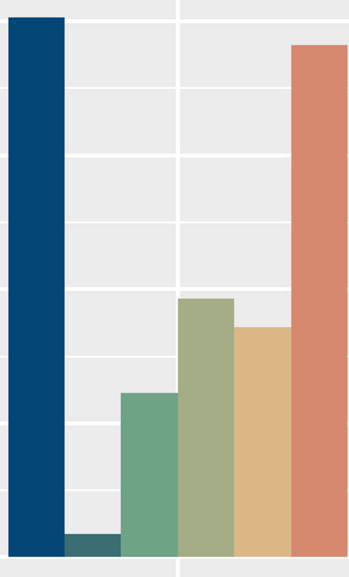

Th0179

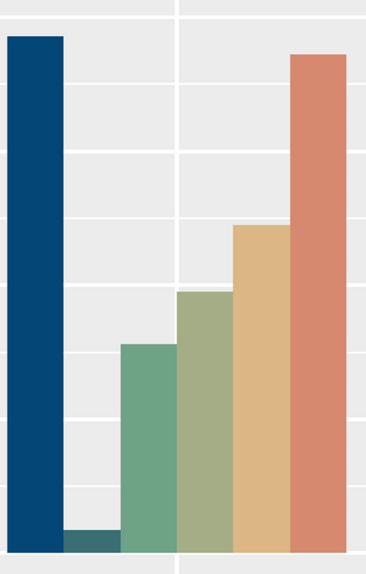

Th3844

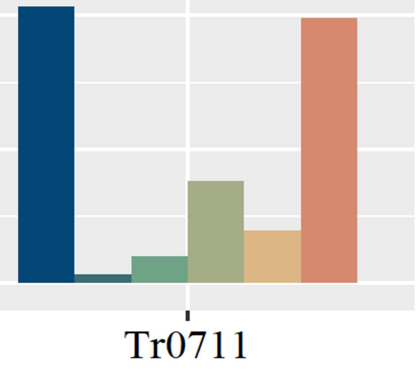

Strains
DOWNSTREAM

EXON

GENE

INTERGENIC

TRANSCRIPT

UPSTREAM

thams 